\title{
Human costs of the first wave of the COVID-19 pandemic in the major epicentres in Italy
}

\author{
Simone Ghislandi ${ }^{1}{ }^{(0)}$, Raya Muttarak ${ }^{2}$, Markus Sauerberg ${ }^{3}$ \\ and Benedetta Scotti ${ }^{1, *}$
}

\section{Abstract}

Deaths from COVID-19 can be miscounted due to under-reporting and inaccurate death registration. Mortality is often reported at the national level, which can result in the underestimation of the true scale of the impact of the pandemic since outbreaks tend to be localised. This study exploits all-cause daily death registration data provided by the Italian Statistical Office (ISTAT) from 1 January to 31 October to estimate the excess mortality and the corresponding changes in life expectancy during the first wave of the COVID-19 pandemic. Focusing on the five most severely hit provinces in Italy (Bergamo, Brescia, Cremona, Lodi and Piacenza), we calculate the excess mortality in 2020 compared to the average mortality of the years 2015 to 2019. Moreover, we estimate the excess mortality in the first quadrimester of 2020, and the annual life expectancy at birth. The estimated excess deaths show that during this period, mortality was significantly higher than the official mortality statistics for COVID-19. According to our estimates for the first quadrimester, life expectancy in the five provinces declined by 5.4 to 8.1 for men and by 4.1 to 5.8 years for women. In addition, we find that annual life expectancy decreased by 2.4 to 4.1 years for men and by 1.9 to 2.8 years for women compared to the 2015-2019 average. Thus, we conclude that the first wave of the COVID-19 pandemic had a substantial impact on population health in the hardest hit areas in Italy.

Keywords: COVID-19; death registration; excess mortality; first wave; Italy; life expectancy; pandemic

\footnotetext{
${ }^{1}$ Department of Social and Political Sciences, Bocconi University, Milan, Italy

${ }^{2}$ International Institute for Applied Systems Analysis (IIASA), Wittgenstein Centre for Demography and Global Human Capital (IIASA, OeAW, University of Vienna), Schlossplatz, Laxenburg, Austria

${ }^{3}$ Vienna Institute of Demography (OeAW), Wittgenstein Centre for Demography and Global Human Capital (IIASA, OeAW, University of Vienna), Vienna, Austria

Authors are listed in alphabetical order.

*Correspondence to: Benedetta Scotti, benedetta.scotti@unibocconi.it
}

DOI: 10.1553/populationyearbook2022.res2.1 


\section{Introduction}

As European countries are struggling to contain the third wave of the coronavirus disease 2019 (COVID-19) pandemic and limit the spread of the more infectious and deadlier new variants of the virus, governments face a difficult trade-off between supporting the economy and protecting public health. Therefore, it is crucial that officials understand the direct and indirect health effects of the pandemic when making policy decisions.

COVID-19-related mortality is one key indicator that is widely used to track the severity and the public health effects of the pandemic. When the pandemic began in early 2020, most of the existing literature on the impact of the pandemic relied on case-fatality rates (CFR) as a measure of mortality (CDC COVID-19 Response Team, 2020; Giangreco, 2020; Khafaie and Rahim, 2020; Onder et al., 2020). However, CFR are not informative for international and historical comparisons. Since they are calculated as the number of deaths divided by the number of confirmed cases, the absence of an accurate estimation of the infection rates in a reference population makes the denominator in the CFR reliant on testing strategies and capacities.

There is no uniform way of classifying, recording and reporting COVID-19 deaths (Garcia-Basteiro et al., 2020). Moreover, when the epidemic worsens, the counting of fatalities becomes more difficult. People who die at home or in longterm care facilities might not be tested at all simply because resource allocation prioritises emergency operations (Iacobucci, 2020; O'Dowd, 2020). Likewise, there may be indirect mortality effects due to congestion in healthcare services (The Lancet Oncology, 2020), or to patients with chronic conditions avoiding visiting health facilities because they are concerned about the risk of COVID-19 infection (Weinberger et al., 2020). Therefore, COVID-19 mortality reports that rely on data on COVID-19-attributed deaths are likely to undercount the pandemic's death toll.

With the release of mortality surveillance data, such as all-cause mortality data from vital statistics systems for various countries, recent studies have used the "excess deaths" approach to estimate the mortality burden of the COVID-19 pandemic (Rivera et al., 2020; Rossen, 2020; Stang et al., 2020; Vandoros, 2020). Excess mortality counts the total number of persons who have died, regardless of the cause of death, relative to the number of deaths that would have normally been expected for a given place and time. For instance, Modi et al. (2020) compared excess mortality data for Lombardy with the official fatality statistics for Italy, and found that the estimated excess mortality in Lombardy between January and April 2020 was about three times higher than the COVID-19 death rate reported in the official data. Thus, this measure allowed the authors to capture both under-reported COVID-19-related deaths and fatalities that could be indirectly attributed to a lack of health care access, economic deprivation or other causes.

While excess mortality is a useful measure of the health impact of the COVID19 pandemic, using overall crude death rates or the proportion of deaths for 
cross-national or historical comparisons is not very informative, because these indicators are affected by the age distribution of the populations studied. By contrast, life expectancy, which is calculated based on human mortality data aggregated in life tables, is insensitive to the age structure of the population, and can therefore reflect differences in mortality reasonably well. Against this background, this study aims to measure the impact of the first wave of COVID-19 on life expectancy at birth by focusing on the hardest hit areas in Italy. As Italy was the first western country severely affected by a large COVID-19 outbreak, this approach allows us to reasonably capture the human cost of the first wave of the COVID-19 pandemic, especially in a context in which non-pharmaceutical interventions were delayed.

In particular, this study focuses on specific geographical areas in Italy that were the most severely affected by the early stages of the COVID-19 pandemic: four provinces in Lombardy (Bergamo, Lodi, Cremona, Brescia) and one province in Emilia Romagna (Piacenza). In modelling the spread of COVID-19 in Italy, Gatto et al. (2020) highlighted the importance of considering the spatial nature of the progress of the wave of infections. The selected provinces experienced the highest numbers of excess deaths in Italy in the observation period compared to the average mortality levels in the years 2015-2019. The highly clustered nature of local transmission resulted in a high concentration of severe illnesses and deaths in one area (Jia et al., 2020). Therefore, the direct impact of COVID-19 on mortality and average life expectancy was likely felt at the sub-national level, rather than at the national level. Indeed, our results suggest that even in Lombardy - which was the hardest hit region in Italy during the first wave of the pandemic (Sebastiani et al., 2020) - the reduction in life expectancy due to COVID-19 was significantly lower than in Bergamo, the province that contributed one-third of the total excess mortality in the Lombardy region. Thus, spatial granularity is needed to assess the full scale of the impact of the pandemic on human life.

Drawing on daily death registration data published by the Italian Statistical Office (ISTAT) for the period of 1 January to 31 October 2020, the present study compares the mortality rates in 2015-2019 and in 2020 across age and gender categories, and provides estimates of the changes in life expectancy following the first wave of the COVID-19 pandemic. While measures such as mortality rates are no doubt useful, they need to be collapsed in an index that is universal enough to provide a reliable measure of all of the human lives lost. By contrast, life expectancy is significantly related to the overall wellbeing of the population, and can therefore provide a simple, objective and immediate measure of the human casualties associated with unprecedented shocks, such as the COVID-19 pandemic (Aburto et al., 2020; Ghislandi et al., 2019; Sen, 1998). Furthermore, as reliable measures of life expectancy are available for some countries from the $19^{\text {th }}$ century onwards, we can use life expectancy for historical comparisons of the human costs associated with major events. 


\section{Institutional and geographical contexts of the hardest hit areas}

In the early hours of 21 February 2020, the first severe case of local transmission of COVID-19 was diagnosed in Europe at a small hospital in Codogno, a municipality in the province of Lodi, south-east of Milan (Paterlini, 2020). Initially, authorities reacted by tracing the connections of patient one, but ultimately failed to identify a patient zero. As early as 24 February 2020, 11 municipalities in the province of Lodi were placed under strict measures to contain the spread of the disease, and were declared a quarantine "red zone". Meanwhile, another cluster of COVID-19 cases emerged in Alzano Lombardo and Nembro, two municipalities in the province of Bergamo, north-east of Milan. In response to the rapid rise in the number of detected cases, especially in the municipalities surrounding these two epicentres, the Italian government announced on 8 March 2020 that it was imposing a (partial) nationwide lockdown starting on 9 March, followed by a total lockdown of all non-essential activities starting on 23 March (Galizzi and Ghislandi, 2020). While the Italian government was praised by the World Health Organization (WHO) for implementing such drastic measures (i.e., restrictions that had not been employed in modern democratic nations since World War II), the virus had already been spreading undetected in the northern part of the country since December 2019 (La Rosa et al., 2021). Thus, it appears that these containment measures were imposed a little too late (Signorelli et al., 2020). During this first wave of the pandemic, the outbreak put an unprecedented burden on the Italian healthcare system, resulting in an exceptionally high number of coronavirus deaths.

Geographically, Lodi and Codogno - two of the 12 provinces in Lombardy - are close to the other two provinces included in our sample: Cremona and Piacenza (see Figures A.1 and A.2 in the Appendix for the geographical location of the provinces being studied). The epidemic wave involving these provinces is thus considered as part of the Lodi-Codogno cluster. Bergamo and Brescia are located north-east of Milan, and, even though the first severe cases of COVID-19 were detected in these provinces just one day after patient one was identified in Lodi, they experienced a week-long delay in the arrival of the first epidemic wave (Galizzi and Ghislandi, 2020).

Of the regions in Italy, Lombardy is the most populated, and it has the highest Gross Domestic Product (GDP). Overall, one-sixth of the Italian population live in Lombardy, and the region produces one-fifth of the country's GDP. Lombardy is relevant for our analysis, because it was the region in Italy that was hardest hit by the COVID-19 pandemic during the first wave, accounting for almost $50 \%$ of the human casualties in the entire country (Odone et al., 2020). Indeed, with the exception of Piacenza (located in the Emilia Romagna region), a province that borders the Lombardy region, all of the other four hardest hit provinces included in the analysis are located in Lombardy. Thus, in the following, we will also present statistics for the region of Lombardy. 


\section{Materials and methods}

\subsection{Data}

We rely on a compendium of administrative data provided by the Italian National Institute of Statistics (ISTAT) that covers all municipalities in Italy (7,903 as of 2020). Specifically, we combine three main datasets. First, we compile daily death counts for all causes at the municipality level, disaggregated by sex and five-year age classes, between 2015 and 2020. For the calendar year 2020, they cover the period between 1 January and 31 October; while for the calendar years 2015-2019, they cover the period between 1 January and 31 December. Second, we obtain data on the resident population at the municipality level, disaggregated by sex and single-year age classes, on 1 January of the years 2015-2020. We reclassify the age classes to five-year age groups to match those used by ISTAT for daily death counts, and aggregate the data accordingly. Third, we use data on monthly (live) births and deaths, disaggregated by sex, at the municipality level from January 2015 to December 2019.

\subsection{Estimation procedure for excess mortality}

Excess mortality is measured in any day $t$ of 2020 as the difference between the observed and the expected number of deaths in 2020 in $t$. The expected number of deaths in $t$ is defined as the average number of deaths observed in $t$ over the period 2015-2019:

$$
{ }_{n} D_{x}^{\text {excess }}\left(t_{2020}\right)={ }_{n} D_{x}^{\text {observed }}\left(t_{2020}\right)-{ }_{n} D_{x}^{\text {expected }}\left(t_{2020}\right)
$$

with

$$
{ }_{n} D_{x}^{\text {expected }}\left(t_{2020}\right)=\frac{1}{5} \sum{ }_{n} D_{x}\left(t_{2015-2019}\right)
$$

where the number of deaths in the age interval $x$ to $x+n$ at time $t$ is defined as ${ }_{n} D_{x}(t)$.

\subsection{Estimate procedures for life expectancy}

Life expectancy is calculated for two different reference periods: the life expectancy for the first quadrimester (i.e., life expectancy for the first four months of the year), and the period (annual) life expectancy (i.e., life expectancy for the entire calendar year).

Since the excess mortality wave was over by the end of April in all of the provinces (Blangiardo et al., 2020), we calculate the first quadrimester life expectancy for the period of 1 January to 30 April for the years 2015-2020 (for men and women separately). To do so, we calculate the first quadrimester 
age- and sex-specific mortality rates for each year. We aggregate the daily death counts (the numerators) over the period of 1 January to 30 April at the provincial level (and at the regional level for Lombardy). The corresponding exposures (i.e., the denominators) are estimated as follows. Starting from the estimated resident population on 1 January, we count the age-specific person-days up to 30 April of each year. Theoretically, these counts are a function of four demographic events: namely, births, ageing, migration and deaths. The daily inflow of births is estimated by using monthly birth data, and assuming that these births are uniformly distributed throughout the month. Since the monthly births for 2020 are not available, we estimate monthly births over 2020 in each province by sex by means of linear extrapolation using province-specific data on monthly live births by sex between January 2015 and December 2019. The effect of ageing - i.e., individuals might be in transition into and out of a given age interval - is modelled by giving each individual the probability of $1 / 365$ of turning one year older during the observation period. The outflows due to deaths are straightforward, as the age-specific death counts are known on a daily basis. We assume no migration. ${ }^{1}$ Formally, the exposed population at day $t$ in age group $x$ in province $p$ is given by the population alive at day $t-1$ in age group $x$ in province $p$ plus those who age into age group $x$ at day $t$ minus those who either die in age group $x$ or age out of the age group $x$ in day $t$ in province $p$ :

$$
{ }_{n} E_{x}^{p}(t)=P_{x}^{p}(t-1)+{ }_{n} A g e_{i n_{x}}^{p}(t)-D_{x}^{p}(t)-{ }_{n} A g e_{\text {out }_{x}}^{p}(t)
$$

We express the obtained daily exposure values in terms of person-years by multiplying them by $1 / 365$ (1/366 for leap years). Then, we derive age-specific mortality rates for the period of 1 January to 30 April by dividing $D_{x}^{p}(t)$ by $E_{x}^{p}(t)$. Finally, life tables are built following the standard procedures outlined by the Human Mortality Database protocol (Wilmoth et al., 2019).

While first quadrimester life expectancy does not require any assumptions and relies entirely on observed data, annual life expectancy needs assumptions on mortality trends for the rest of the year 2020 after 31 October when the available ISTAT data on all-cause mortality at the municipality level end. Given the timing of the second wave, which hit Italy in mid-October 2020, harvesting (i.e., the reduction in mortality rates following peak mortality associated with shock events) can be excluded. Thus, we assume that in November and December 2020, mortality returned to the average levels recorded in 2015-2019. It should be noted that this is a conservative approach, since the mortality levels in November and December are expected to be higher than in 2015-2019 due to the unfolding of the second epidemic wave. As we do not know the daily distribution of deaths after 31

\footnotetext{
1 The no-migration assumption is fairly realistic. Due to the travel restrictions to and from Italy, and also within the country, it may be expected that migration flows declined. Indeed, the existing data suggest that labour migration as well as refugee admissions were far lower in 2020 than in 2019 (EASO, 2020; EMN/OECD, 2020; OECD, 2020).
} 
October, we assume that the deaths were distributed uniformly across November and December 2020.

We then proceed with the estimation of population exposure for each day between 1 January and 31 December 2020 following the same procedure detailed above (sex- and age-specific population estimates by province are reported in Table A.1). Finally, we aggregate the death counts and population exposure values over the entire year to derive the age-specific mortality rates and life expectancies under both scenarios. For the calendar years 2015-2019, we compute the age-specific mortality rates by dividing the total annual death counts over the mid-year population, and derive the life expectancies accordingly.

We estimate confidence intervals for both the first quadrimester and the annual life expectancies by bootstrapping using Monte Carlo simulation methods, assuming the death counts follow a binomial distribution (Andreev and Shkolnikov, 2010; Chiang, 1984).

\section{Results}

Figures 1 (a)-1(f) show the trends in daily mortality for the five provinces with the highest numbers of declared cases in Italy and in the whole Lombardy region. ${ }^{2}$ Plotting the mortality distribution by age groups allows us to fully capture the progression of the first epidemic wave. It is evident that the epidemic curve inflated with age across all provinces. It is also clear that by 30 April, the daily mortality in all selected provinces approached the pre-pandemic values (i.e., no excess mortality). Hence, the wavelength of the epidemic in these provinces was between six and eight weeks, with the peak happening around two weeks after the onset of the outbreak.

The vertical lines show four relevant dates for the evolution of the first epidemic wave. After the case of patient one was first identified in Codogno, located in the province of Lodi, the authorities quickly locked down 11 municipalities in the area on 24 February 2020. The containment measures associated with the lockdown were not implemented in other provinces until after 8 March. Although the earlier lockdown enabled Lodi to flatten the curve more effectively than other severely affected provinces (Figure 1), the province still experienced a notable increase in excess mortality. Considering that the incubation period - i.e., the time between the exposure and the onset of symptoms - can be up to 24 days, it is evident that the lockdown was imposed too late in these provinces. While political reasons prevented the authorities from implementing the lockdown earlier in the provinces where the number of cases had been rising rapidly, like in Bergamo, there is recent evidence showing that COVID-19 had already been circulating undetected in northern Italy

2 All figures for the Lombardy region cover all 12 provinces in the region. 
Figure 1(a):

Trends in total daily death counts in the province of Bergamo January 1 and October 312020 vs. 2015-2019 average

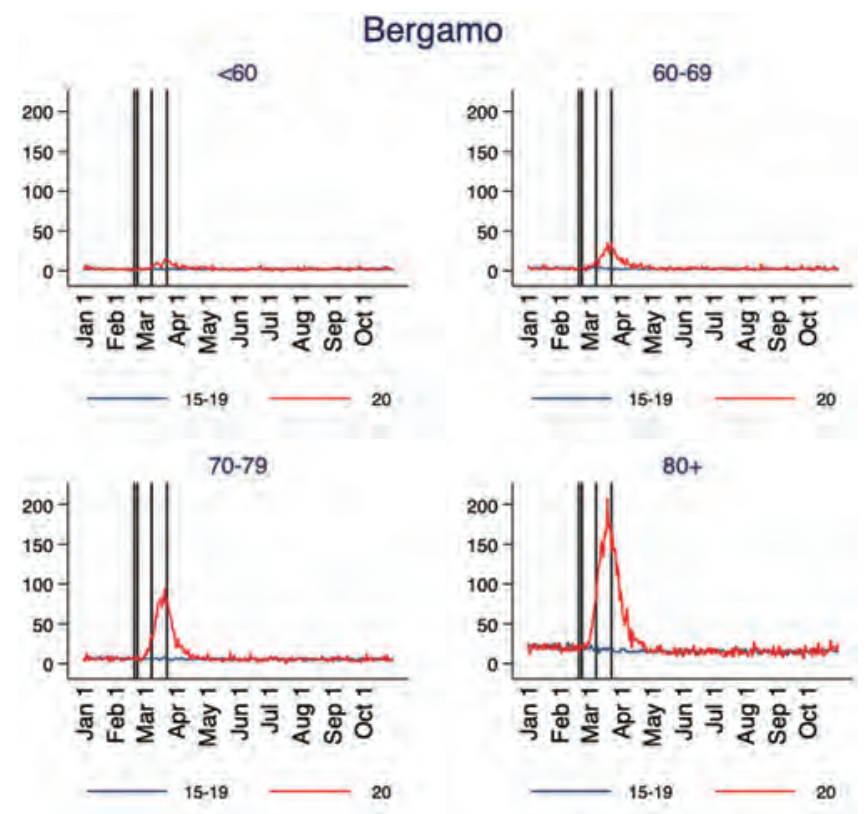

Note: The vertical lines show relevant dates for the evolution of the epidemic. The vertical lines indicate the following relevant days: 20 February = patient one found in Codogno; 23 February = red zones in Codogno. Schools and Universities in affected regions are closed; 8 March $=$ orange zones were established in Lombardy and Piacenza; 23 March = all non-essential economic activities were closed.

since December 2019 (La Rosa et al., 2021). Thus, our study proxies the impact of the COVID-19 outbreak in the absence of containment interventions.

The geographical distribution of excess deaths in the first quadrimester across Italy (Figure 2) matches the distribution of confirmed cases (which comprise the deceased, the recovered individuals and the active cases) provided by the Italian Civil Protection Department, which publishes the official surveillance data on COVID-19. ${ }^{3}$ This geographical pattern indicates that the excess mortality observed in our data represents mortality directly and indirectly related to COVID-19.

Note that in Figure 2, we focus on the 1 January-30 April period only in order to better capture the impact of the first wave of the COVID-19 pandemic. Compared to the average number of people who died in the same period in the previous five years (2015-2019), the excess number of deaths (for those aged 40 or older)

3 Official statistics on COVID-19 cases and deaths provided by the Italian Civil Protection Department are available at http://www.protezionecivile.gov.it/home (Situation Map). 
Figure 1(b):

Trends in total daily death counts in the province of Brescia January 1 and October 312020 vs 2015-2019 average

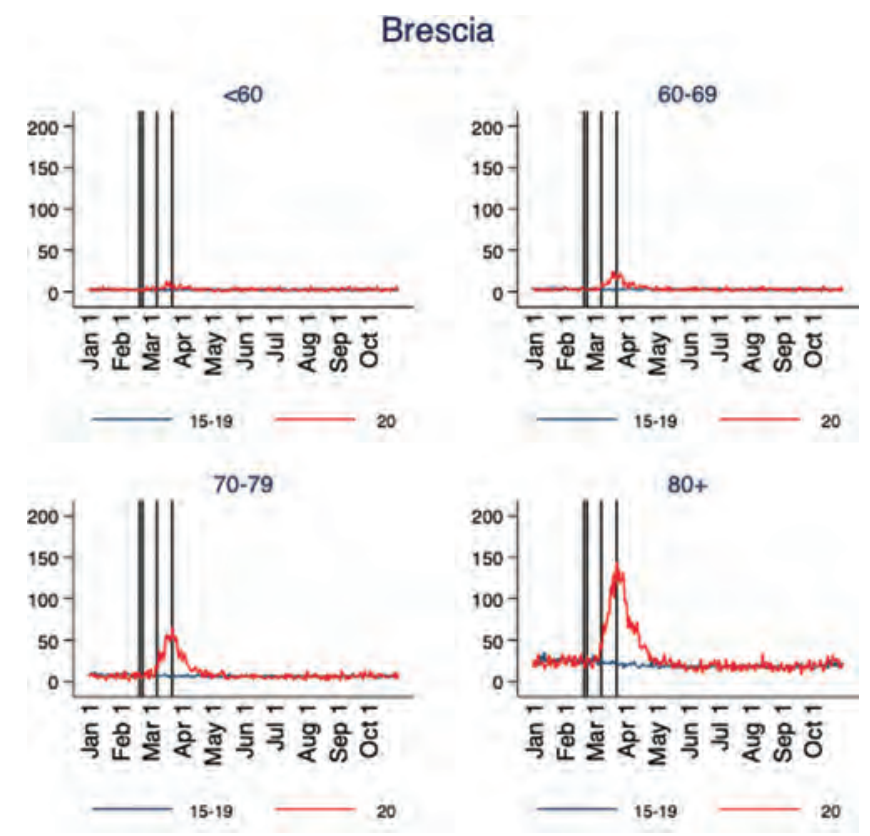

Notes: The vertical lines show relevant dates for the evolution of the epidemic. The vertical lines indicate the following relevant days: 20 February = patient one found in Codogno; 23 February = red zones in Codogno. Schools and Universities in affected regions are closed; $8 \mathrm{March}=$ orange zones were established in Lombardy and Piacenza; $23 \mathrm{March}=$ all non-essential economic activities were closed.

between 1 January and 30 April 2020 sums to 6,084 in Bergamo, 3,969 in Brescia, 2,030 in Cremona, 905 in Lodi and 1,170 in Piacenza. For the entire region of Lombardy, the excess number of deaths is approximately 23,649 (Table 1). The total number of COVID-19 deaths reported by the Italian Civil Protection Department for Lombardy as of 30 April 2020 is 13,772. This implies that the overall death toll of the first epidemic wave was about $70 \%$ higher than that suggested by official statistics on COVID-19 deaths. The mortality rate in the first quadrimester of 2020 increased substantially in all provinces and for all age groups, with the largest increase being observed for men aged 70-79 in Bergamo (a 347\% increase). Age clearly represented a risk factor for excess mortality, in line with the age gradient in COVID-19 CFR observed in Italy and elsewhere. For instance, among the excess deaths observed in Bergamo, the mortality rate was much higher among older men aged $\geq 70$ years. A similar ratio is found in the other provinces.

When we only consider the distribution of excess mortality without adjusting for population size in each age-sex category, we observe slightly more excess mortality 
Figure 1(c):

Trends in total daily death counts in the province of Cremona January 1 and October 312020 vs. 2015-2019 average

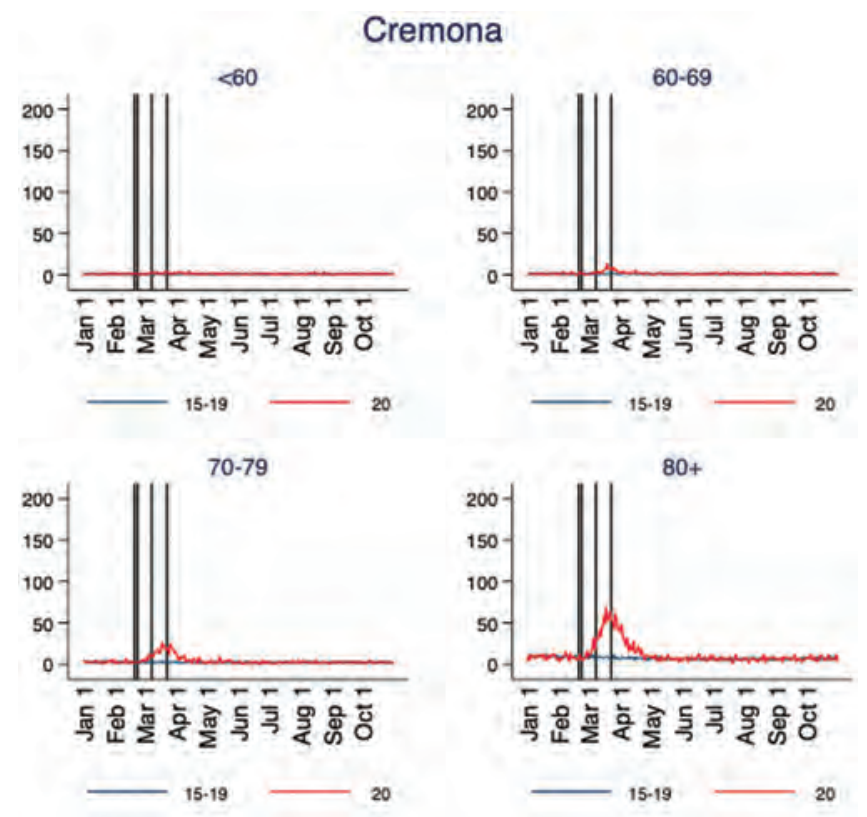

Notes: The vertical lines show relevant dates for the evolution of the epidemic. The vertical lines indicate the following relevant days: 20 February = patient one found in Codogno; 23 February = red zones in Codogno. Schools and Universities in affected regions are closed; $8 \mathrm{March}=$ orange zones were established in Lombardy and Piacenza; $23 \mathrm{March}=$ all non-essential economic activities were closed.

in men than in women (53\% of excess deaths involved male subjects). However, when we consider the mortality risk ratio between the sexes, we find that the excess mortality for males was consistently higher than that for females across all age groups and provinces (relative risk $\geq 1$ ).

The trends in the first quadrimester and the annual life expectancies are illustrated in Figures 3 and 4. When we look at the trends in the first quadrimester of 2020, it is evident that the drop in life expectancy was significant for both men and women in all provinces. Compared to the average life expectancy of the 20152019 period, the reduction for men ranged from 5.5 years in Brescia to 8.1 years in Bergamo, and the reduction for women ranged from 4.1 years in Piacenza to 5.8 years in Bergamo. The larger reduction in the first quadrimester life expectancy for men was due to sex differentials in the COVID-19 mortality risk, as both the official case fatality data and our death registration data consistently show. Indeed, when we decompose the loss in life expectancy to identify which age groups contributed the most to the reduction in life expectancy (Figure A.3 in Appendix), it becomes clear 
Figure 1(d):

Trends in total daily death counts in the province of Piacenza January 1 and October 312020 vs 2015-2019 average

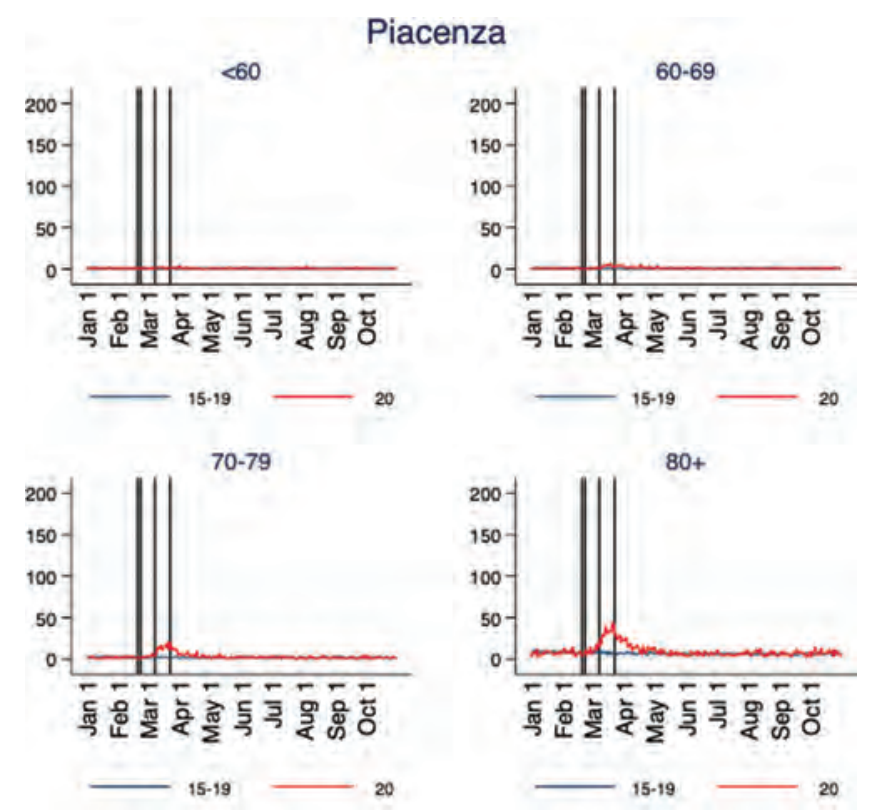

Notes: The vertical lines show relevant dates for the evolution of the epidemic. The vertical lines indicate the following relevant days: 20 February = patient one found in Codogno; 23 February = red zones in Codogno. Schools and Universities in affected regions are closed; 8 March = orange zones were established in Lombardy and Piacenza; $23 \mathrm{March}=$ all non-essential economic activities were closed.

that the older populations, and especially men aged 60-79 years, played a major role.

When life expectancy is extrapolated for the whole year, the loss in life expectancy is diluted over a longer period. Thus, the drop in life expectancy due to COVID-19related excess mortality was less steep than that observed in the first quadrimester life expectancy.

In the most severely hit province of Bergamo, life expectancy dropped by 4.1 years for men and 2.8 years for women when compared to life expectancy for the years 2015-2019. In the slightly less affected provinces of Brescia, Cremona, Lodi and Piacenza, the reduction in life expectancy ranged between 2.4 in Brescia and 3.8 in Cremona for men, and between 1.9 in Piacenza and 2.6 in Cremona for women. As expected, the reduction in life expectancy was smaller in Lombardy, at 1.9 years for males and 1.5 years for females.

When we turn to the national level, we see that the results are extremely heterogeneous (Figure 5). It is evident that the higher excess mortality experienced in the northern part of Italy, particularly in Lombardy, was not experienced in most 
Figure 1(e):

Trends in total daily death counts in the province of Lodi January 1 and October 31 2020 vs. 2015-2019 average

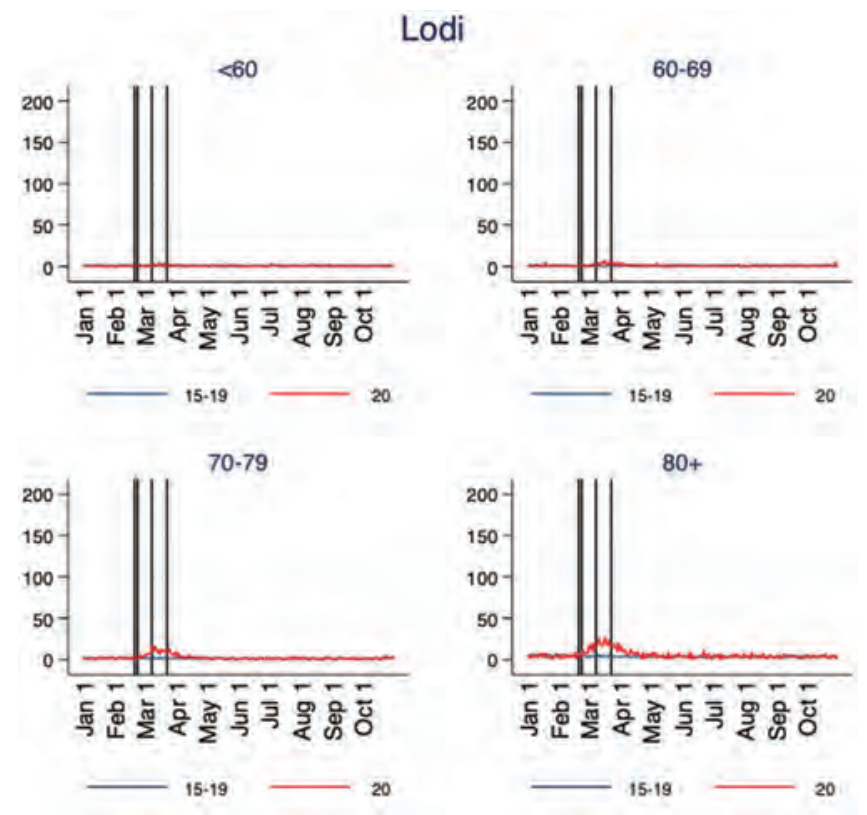

Notes: The vertical lines show relevant dates for the evolution of the epidemic. The vertical lines indicate the following relevant days: 20 February = patient one found in Codogno; 23 February = red zones in Codogno. Schools and Universities in affected regions are closed; $8 \mathrm{March}=$ orange zones were established in Lombardy and Piacenza; $23 \mathrm{March}=$ all non-essential economic activities were closed.

of the provinces of the central part and the south of the country. For example, in provinces like Sassari and Nuoro in Sardegna and Cosenza in Calabria, the lockdown reduced mortality in the first four months of the year, resulting in an estimated increase in life expectancy up to two years for both men and women.

\section{Discussion}

By avoiding the inconsistencies in the classification of causes of death and in testing practices, and by focusing on the five areas in Italy that were most severely affected by the first wave of the pandemic, this study provided an assessment of the full impact of the first wave of the COVID-19 pandemic on human life.

Two empirical regularities clearly emerged when we looked at demographic differentials. First, the age gradient in excess mortality was steep, and age was the most evident risk factor for COVID-19 mortality. In Lombardy, men and women 
Figure 1(f):

Trends in total daily death counts in the region of Lombardy January 1 and October 312020 vs. 2015-2019 average

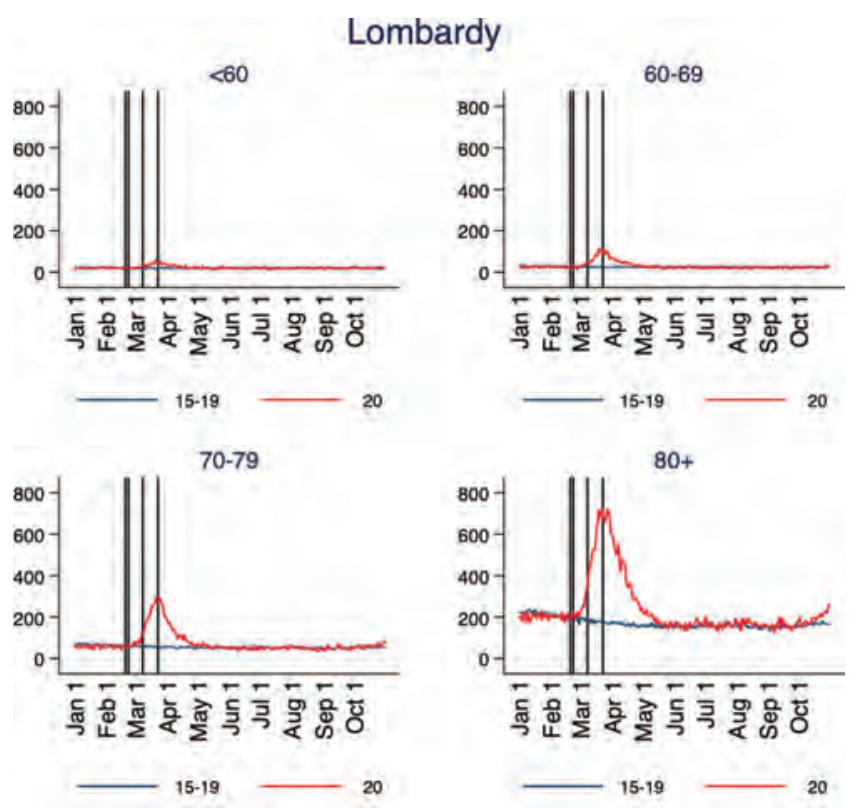

Notes: The vertical lines show relevant dates for the evolution of the epidemic. The vertical lines indicate the following relevant days: 20 February = patient one found in Codogno; 23 February = red zones in Codogno. Schools and Universities in affected regions are closed; 8 March = orange zones were established in Lombardy and Piacenza; $23 \mathrm{March}=$ all non-essential economic activities were closed.

over age 70 were 23 times more likely to die than their counterparts under age 70 . These patterns were replicated in all five provinces. Therefore, areas where older people made up a high proportion of the population (e.g., 17\% of the population were over age 70 in the Lombardy region in 2019) had a higher burden of COVID19 mortality (Dowd et al., 2020). Second, within each province, the risk of dying was consistently higher for men than for women for all age classes and provinces considered. Evidence that men are more likely than women to suffer from COVID19 , as measured by hospitalisations, admissions to intensive care units and fatality rates, has been consistently reported for other countries across different studies and subsamples (Gebhard et al., 2020; Peckham et al., 2020; Scully et al., 2020). Higher mortality rates for men than for women translate into a larger reduction in life expectancy for men than for women.

Although these data provided evidence of the severity of the first wave of the COVID-19 pandemic in Europe, a further measurement effort was needed, particularly for geographical and historical comparability purposes. In terms of life expectancy, we showed that for the period of 1 January to 30 April 2020, the 
reduction in the first quadrimester life expectancy, compared with the average of the years 2015-2019, was as high as 8.1 years for men and 5.8 years for women in Bergamo.

When the analysis was extended to the whole year, under the assumption that the mortality rates from November onwards were back to "normal", life expectancy was reduced by up to four years (for men in Bergamo). However, significant uncertainties remain about the longer-term effects of the pandemic on health conditions among, for instance, patients who recovered from COVID-19 with major co-morbidities and mental health issues, and pregnant women. It is also possible that indirect physical and mental health consequences of changing socio-economic conditions affected the mortality patterns in 2020.

What can we say regarding the validity of the no harvesting assumption? Figure 1 provides evidence that after the end of the first wave, the mortality patterns in all age-provinces groups were largely similar to those in the previous years. This result is not consistent with harvesting, which would require negative excess mortality to compensate for the high levels of mortality registered in the first quadrimester. It should also be noted that since November 2020, Italy has been experiencing a severe second wave of infections that has not fully finished. Moreover, since March 2021, the country has been bracing for a third wave. Therefore, mortality in Italy is likely to increase even further. Thus, the figures provided can be considered estimates of the human life lost only for the first wave of the COVID-19 epidemic in the affected provinces.

It should also be noted that in the first quadrimester, some provinces in Italy experienced an improvement in life expectancy thanks to a reduction in mortality compared to the average of the previous years. There may have been spill-over benefits of the lockdown measures that contributed to a decline in premature deaths, such as from road traffic fatalities, alcohol consumption, violence and injuries at work (Qi et al., 2020; Qureshi et al., 2020). Moreover, our observation that the epidemic had a differential impact across different regions within Italy shows the importance of considering specific geographic areas when estimating the effect of the COVID-19 pandemic on human life. Indeed, focusing on national-level statistics only would further bias downward the estimation of the impact of the virus. Thus, our explicit focus on a local context can be considered the main strength of this analysis. Because the COVID-19 outbreaks have been geographically concentrated, looking at country-level life expectancy is misleading, and underestimates the actual impact of the pandemic.

Along with Italy, other European countries have been experiencing sharp declines in life expectancy due to the COVID-19 pandemic. Estimating weekly life expectancy for Spain, Trias-Llimós et al. (2020) found a particularly large drop at the beginning of April 2020, with a decline of up to 7.6 years at the national level. At the regional level, the authors reported an even more pronounced drop in life expectancy, with Madrid in particular experiencing a large reduction, ranging from 11.2 years in week 13 to 14.8 years in week 14 for both men and women. Moreover, the findings of a study for Sweden based on mortality data for the first 33 weeks 


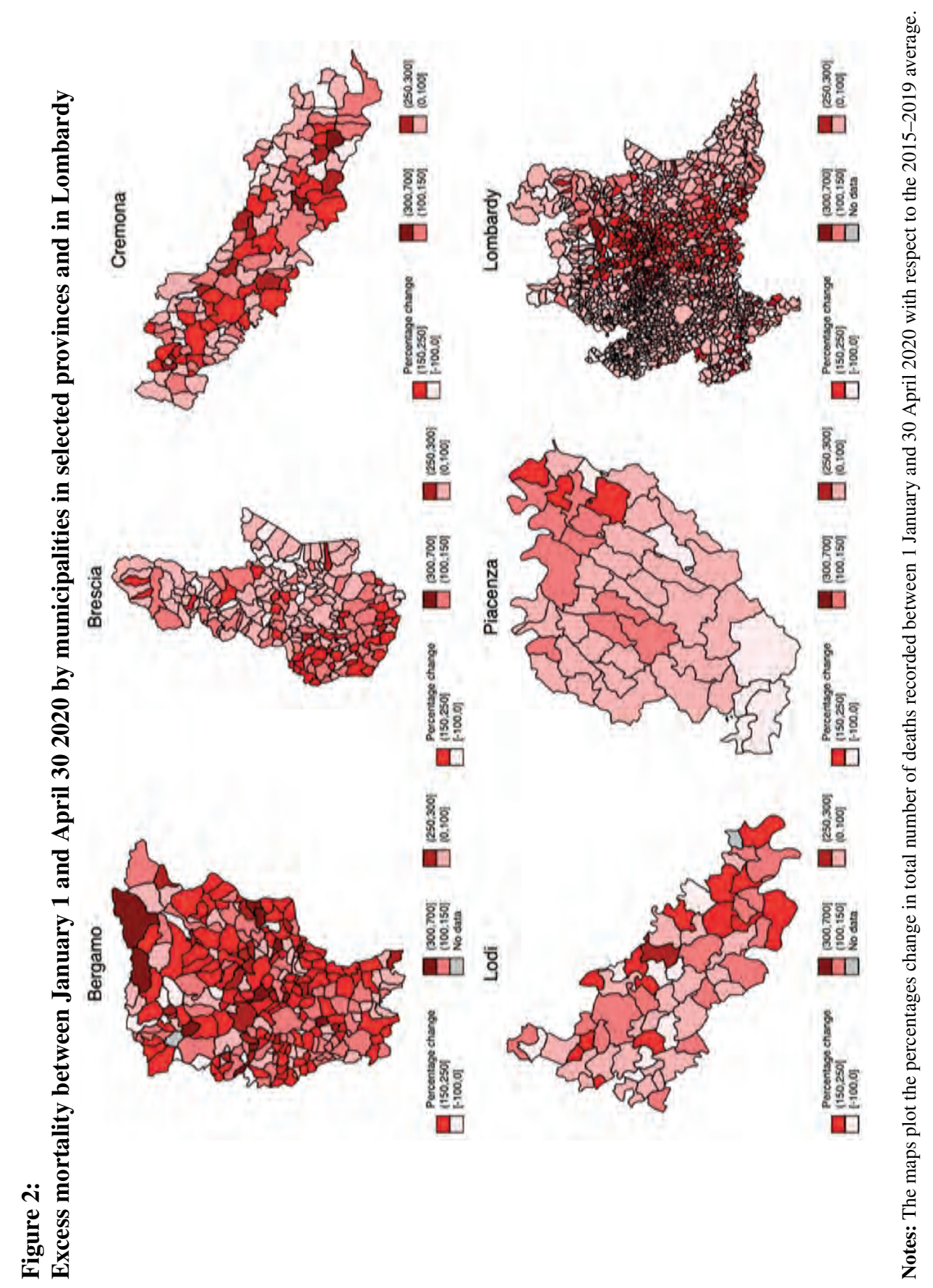




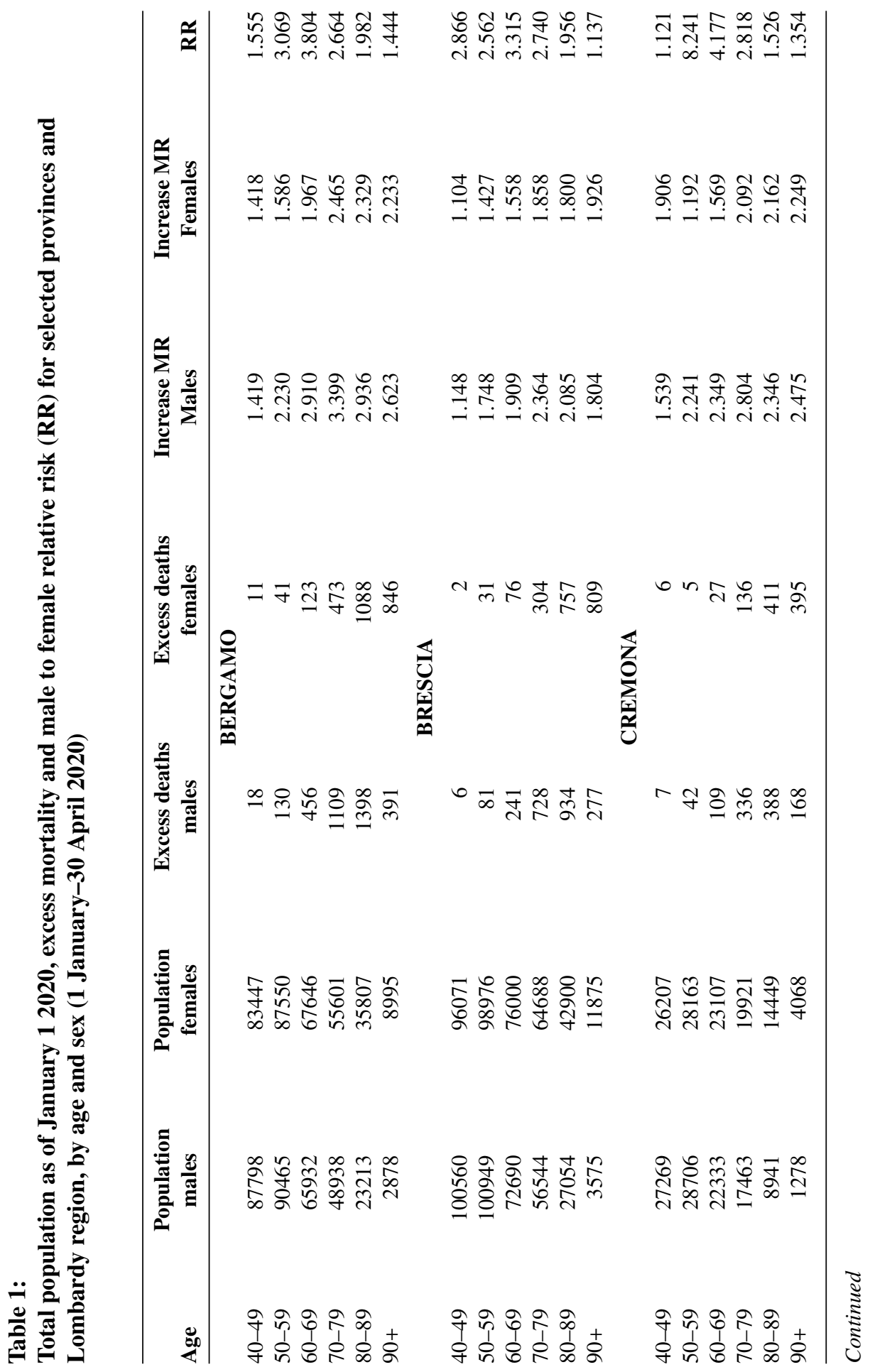




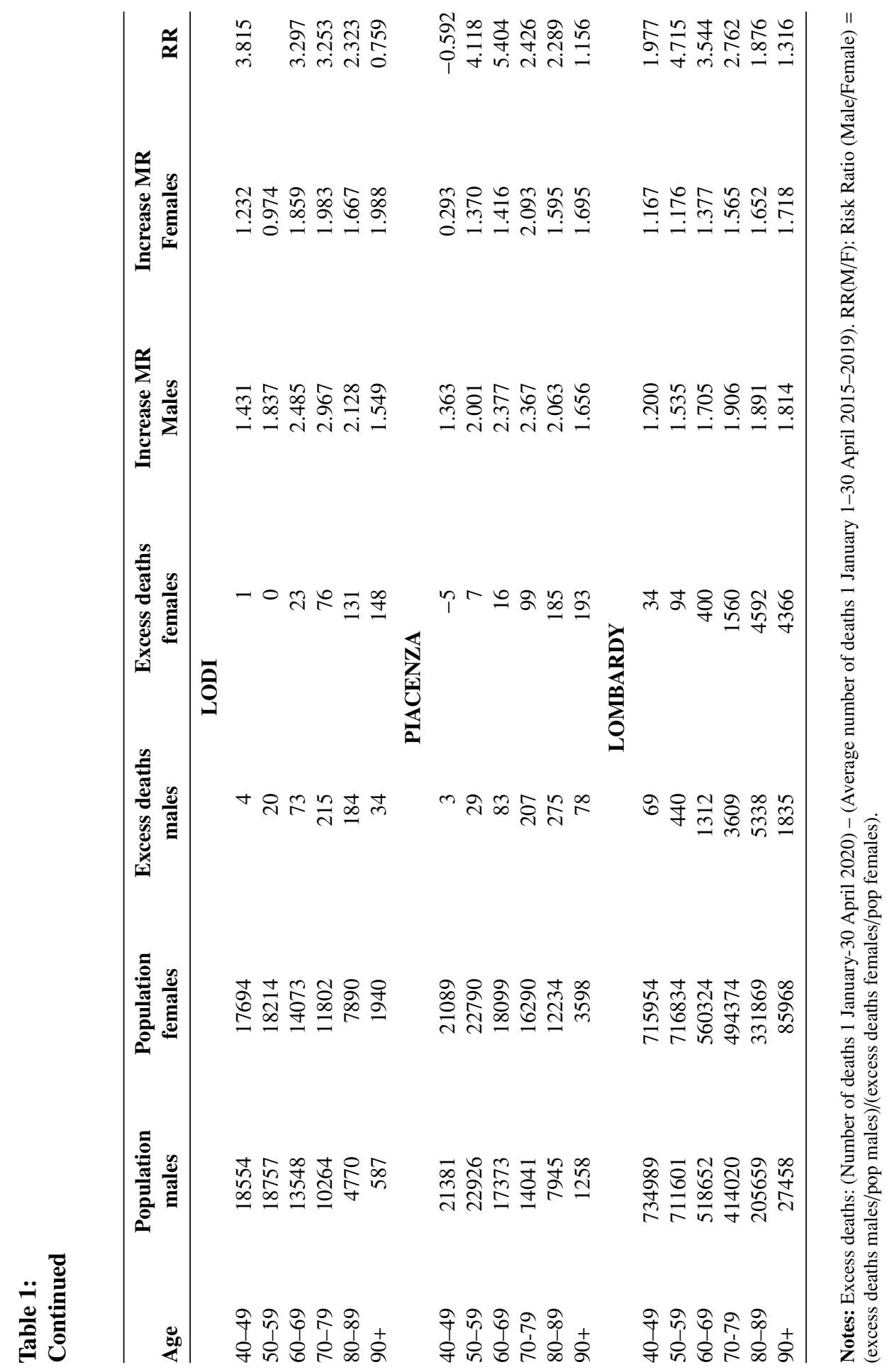


Figure 3:

Estimates of the first quadrimester (1 January-April 30) by sex in selected provinces and in Lombardy (95\% confidence intervals in grey)
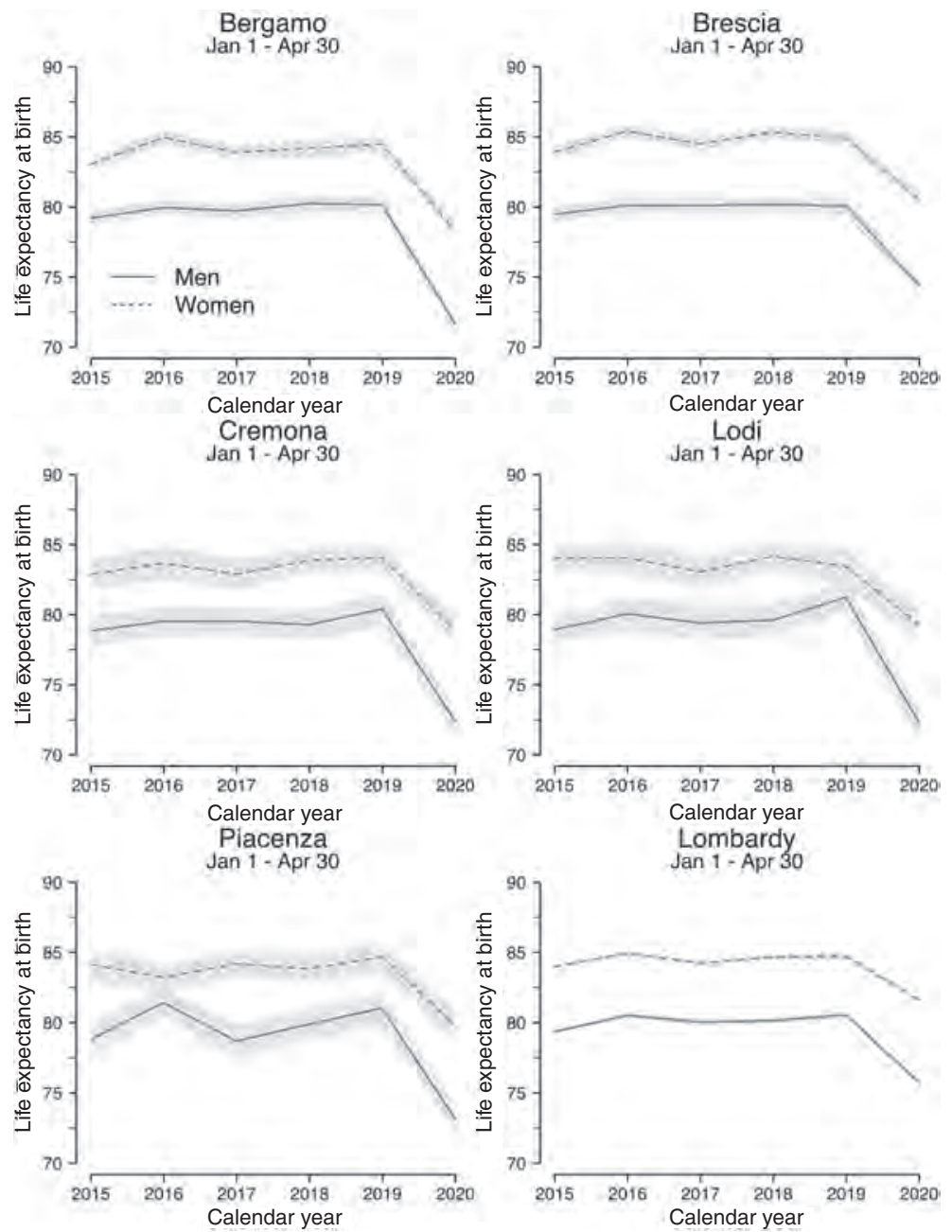

Notes: Confidence intervals (95\%) for life expectancies are estimated by bootstrapping using Monte Carlo simulation methods, assuming death counts follow a binomial distribution.

of the pandemic suggest that life expectancy at age 50 in Stockholm decreased by about two years for men and about 1.5 years for women (Modig et al., 2021). At the national level, the reduction in annual life expectancy during the COVID-19 pandemic is expected to be smaller. Similarly, a study that calculated life expectancy at birth in England and Wales on the basis of data for the first 47 weeks of the 


\section{Figure 4:}

Estimates of the annual life expectancies by sex in selected provinces of Lombardy and in the Lombardy region as a whole ( $95 \%$ confidence intervals in grey)
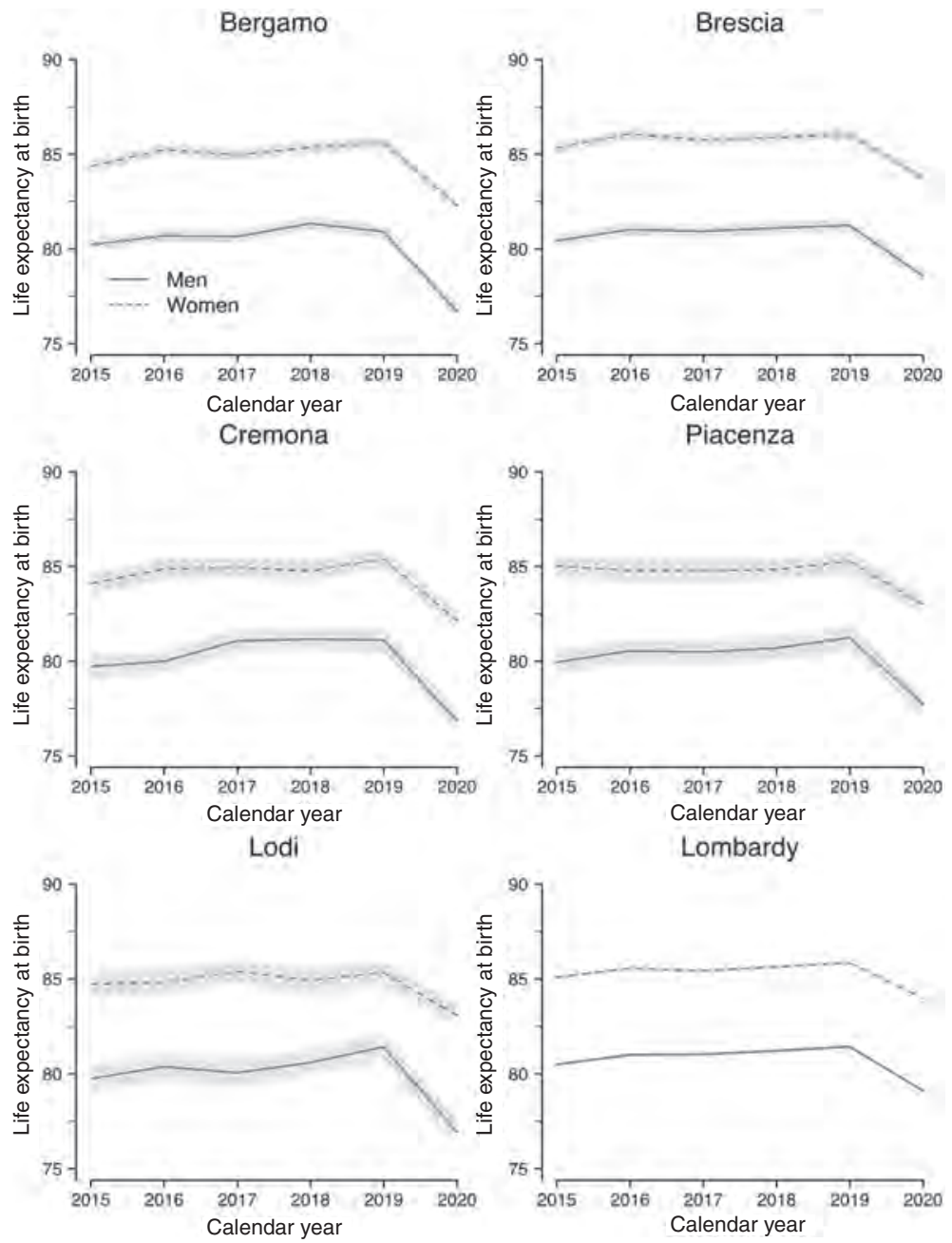

Notes: Confidence intervals (95\%) for life expectancies are estimated by bootstrapping using Monte Carlo simulation methods, assuming death counts follow a binomial distribution.

pandemic found that it declined by 0.9 years for women and 1.2 years for men between 2019 and 2020 (Aburto et al., 2021). Our results are in line with those of these previous studies, as we also found the largest declines in life expectancy at a local level; in our case, in the north of Italy. 
Figure 5:

Differences between life expectancy at birth (ex0) in 2020 in Italian provinces and 2015-2019 average, by sex
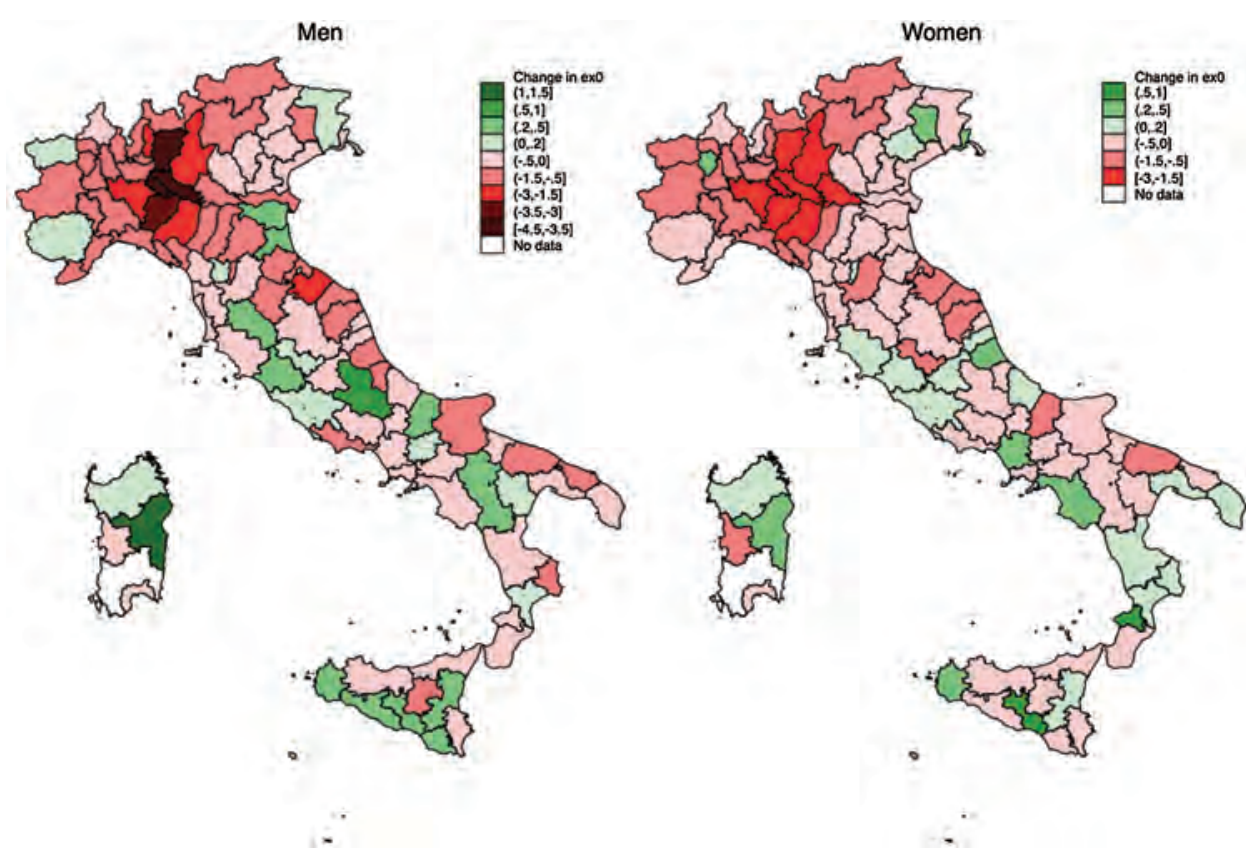

Under normal conditions, life expectancy at birth is calculated with mortality data for one calendar year, and provides an estimate of mean longevity for a hypothetical group of individuals who experience the mortality regime of a given period over their entire life course. Obviously, in reality, no group of people will be exposed over their life course to the mortality regime of the worst hit regions in Italy during the first wave of the COVID-19 pandemic. With the development, approval and rollout of several vaccines and the implementation of protective measures, it is highly likely that in the future, mortality in these regions will bounce back to lower levels. Still, life expectancy is a powerful tool for summarising and comparing mortality rates between regions and over time, especially because it accounts for differences in age-specific mortality (Marois et al., 2020; Trias-Llimós et al., 2020).

As the results of this study show, the cost in terms of human life of the delays in public interventions to reduce the transmission of the virus was disturbingly high. As European countries struggle to manage the successive waves of the coronavirus by striking a balance between protecting public health and reducing the economic effects of restriction measures, it is important to keep in mind the potential risk of viral reintroduction, and the direct and indirect dangers it poses to human life. Well-planned government measures aimed at flattening the epidemic curve while 
preventing a new wave of infections, along with public cooperation in maintaining physical distancing, wearing a face mask and practicing proper hygiene until there is widespread access to vaccination for the novel coronavirus, are key to achieving a balance between protecting public health and sustaining the economy.

\section{Author contributions}

SG and BS designed the research; BS acquired data, performed the analysis and created the display items with the help of MS. SG, RM, MS and BS contributed to the writing of the manuscript.

\section{ORCID}

Simone Ghislandi (I) https://orcid.org/0000-0003-2335-7304

Raya Muttarak ${ }^{\mathbb{D}}$ https://orcid.org/0000-0003-0627-4451

Markus Sauerberg ${ }^{(1)}$ https://orcid.org/0000-0001-9524-446X

Benedetta Scotti ${ }^{(1)}$ https://orcid.org/0000-0001-5528-3659

\section{References}

Aburto, J. M., Kashyap, R., Schöley, J., Angus, C., Ermisch, J., Mills, M. C., and Dowd, J. B. (2021). Estimating the burden of the COVID-19 pandemic on mortality, life expectancy and lifespan inequality in England and Wales: A population-level analysis. Journal of Epidemiology and Community Health. https://doi.org/10.1136/jech-2020-215505

Aburto, J. M., Villavicencio, F., Basellini, U., Kjærgaard, S., and Vaupel, J. W. (2020). Dynamics of life expectancy and life span equality. Proceedings of the National Academy of Sciences, 117(10), 5250-5259. https://doi.org/10.1073/pnas.1915884117

Andreev, E. M., and Shkolnikov, V. (2010). Spreadsheet for calculation of confidence limits for any life table or healthy-life table quantity (MPIDR Technical Report 2010-005). Max Planck Institute for Demographic Research. https://doi.org/10.4054/MPIDR-TR-2010005

Blangiardo, M., Cameletti, M., Pirani, M., Corsetti, G., Battaglini, M., and Baio, G. (2020). Estimating weekly excess mortality at sub-national level in Italy during the COVID-19 pandemic. PLOS ONE, 15(10), Article e0240286. https://doi.org/10.1371/journal.pone. 0240286

CDC COVID-19 Response Team. (2020). Severe outcomes among patients with Coronavirus disease 2019 (COVID-19)—United States, February 12-March 16, 2020. MMWR. Morbidity and Mortality Weekly Report, 69(12), 343-346. https://doi.org/10.15585/mmwr. mm6912e2 
Chiang, C. L. (1984). The life table and its applications (Original ed.). Krieger Publishing Company.

Dowd, J. B., Andriano, L., Brazel, D. M., Rotondi, V., Block, P., Ding, X., Liu, Y., and Mills, M. C. (2020). Demographic science aids in understanding the spread and fatality rates of COVID-19. Proceedings of the National Academy of Sciences, 117(18), 9696-9698. https://doi.org/10.1073/pnas.2004911117

EASO. (2020). Asylum applications remain 31\% lower than in 2019. European Asylum Support Office. https://www.easo.europa.eu/news-events/asylum-applications-remain-31lower-2019

EMN/OECD. (2020). Impact of COVID-19 on remittances in EU and OECD countries EMN-OECD Inform. European Migration Network. https://ec.europa.eu/home-affairs/ sites/homeaffairs/files/docs/pages/00_eu_inform4_remittances_2020_en_0.pdf

Galizzi, M. M., and Ghislandi, S. (2020). Bergamo's response to the coronavirus pandemic. Cambridge Core Blog, 18 April, 2020. https://www.cambridge.org/core/blog/2020/04/18/ bergamos-response-to-the-coronavirus-pandemic/

García-Basteiro, A. L., Chaccour, C., Guinovart, C., Llupià, A., Brew, J., Trilla, A., and Plasencia, A. (2020). Monitoring the COVID-19 epidemic in the context of widespread local transmission. The Lancet Respiratory Medicine, 8(5), 440-442. https://doi.org/10. 1016/S2213-2600(20)30162-4

Gatto, M., Bertuzzo, E., Mari, L., Miccoli, S., Carraro, L., Casagrandi, R., and Rinaldo, A. (2020). Spread and dynamics of the COVID-19 epidemic in Italy: Effects of emergency containment measures. Proceedings of the National Academy of Sciences, 117(19), 1048410491. https://doi.org/10.1073/pnas.2004978117

Gebhard, C., Regitz-Zagrosek, V., Neuhauser, H. K., Morgan, R., and Klein, S. L. (2020). Impact of sex and gender on COVID-19 outcomes in Europe. Biology of Sex Differences, 11(1), 29. https://doi.org/10.1186/s13293-020-00304-9

Ghislandi, S., Sanderson, W. C., and Scherbov, S. (2019). A simple measure of human development: The Human Life Indicator. Population and Development Review, 45(1), 219-233. https://doi.org/10.1111/padr.12205

Giangreco, G. (2020). Case fatality rate analysis of Italian COVID-19 outbreak. Journal of Medical Virology, 92(7), 919-923. https://doi.org/10.1002/jmv.25894

Iacobucci, G. (2020). Covid-19: Care home deaths in England and Wales double in four weeks. BMJ, 369, Article m1612. https://doi.org/10.1136/bmj.m1612

Jia, J., Hu, X., Yang, F., Song, X., Dong, L., Zhang, J., Jiang, F., and Gao, R. (2020). Epidemiological characteristics on the clustering nature of COVID-19 in Qingdao City, 2020: A descriptive analysis. Disaster Medicine and Public Health Preparedness, 14(5), 643-647. https://doi.org/10.1017/dmp.2020.59

Khafaie, M. A., and Rahim, F. (2020). Cross-country comparison of case fatality rates of COVID-19/SARS-COV-2. Osong Public Health and Research Perspectives, 11(2), 74-80. https://doi.org/10.24171/j.phrp.2020.11.2.03

La Rosa, G., Mancini, P., Bonanno Ferraro, G., Veneri, C., Iaconelli, M., Bonadonna, L., Lucentini, L., and Suffredini, E. (2021). SARS-CoV-2 has been circulating in northern Italy since December 2019: Evidence from environmental monitoring. Science of the Total Environment, 750, Article 141711. https://doi.org/10.1016/j.scitotenv.2020.141711 
Marois, G., Muttarak, R., and Scherbov, S. (2020). Assessing the potential impact of COVID19 on life expectancy. PLOS ONE, 15(9), Article e0238678. https://doi.org/10.1371/journal. pone. 0238678

Modi, C., Böhm, V., Ferraro, S., Stein, G., and Seljak, U. (2020). How deadly is COVID-19? A rigorous analysis of excess mortality and age-dependent fatality rates in Italy. MedRxiv. https://doi.org/10.1101/2020.04.15.20067074

Modig, K., Ahlbom, A., and Ebeling, M. (2021). Excess mortality from COVID-19: Weekly excess death rates by age and sex for Sweden and its most affected region. European Journal of Public Health, 31(1), 17-22. https://doi.org/10.1093/eurpub/ckaa218

Odone, A., Delmonte, D., Scognamiglio, T., and Signorelli, C. (2020). COVID-19 deaths in Lombardy, Italy: Data in context. The Lancet Public Health, 5(6): Article E310. https://doi.org/10.1016/S2468-2667(20)30099-2

O'Dowd, A. (2020). Covid-19: Care home deaths in England and Wales rise sharply. BMJ, 369, Article m1727. https://doi.org/10.1136/bmj.m1727

OECD. (2020). International migration outlook 2020. OECD Publishing. https://doi.org/10. 1787/ec98f531-en

Onder, G., Rezza, G., and Brusaferro, S. (2020). Case-fatality rate and characteristics of patients dying in relation to COVID-19 in Italy. JAMA 313(18), 1775-1776. https://doi. org/10.1001/jama.2020.4683

Paterlini, M. (2020). On the front lines of coronavirus: The Italian response to Covid-19. $B M J, 368$, Article m1065. https://doi.org/10.1136/bmj.m1065

Peckham, H., de Gruijter, N. M., Raine, C., Radziszewska, A., Ciurtin, C., Wedderburn, L. R., Rosser, E. C., Webb, K., and Deakin, C. T. (2020). Male sex identified by global COVID19 meta-analysis as a risk factor for death and ITU admission. Nature Communications, 11(1), Article 6317. https://doi.org/10.1038/s41467-020-19741-6

Qi, J., Zhang, D., Zhang, X., Yin, P., Liu, J., Pan, Y., Takana, T., Xie, P., Wang, Z., Liu, S., Gao, G. F., He, G., and Zhou, M. (2020). Do lockdowns bring about additional mortality benefits or costs? Evidence based on death records from 300 million Chinese people. MedRxiv. https://doi.org/10.1101/2020.08.28.20183699

Qureshi, A. I., Huang, W., Khan, S., Lobanova, I., Siddiq, F., Gomez, C. R., and Suri, M. F. K. (2020). Mandated societal lockdown and road traffic accidents. Accident; Analysis and Prevention, 146, Article 105747. https://doi.org/10.1016/j.aap.2020.105747

Rivera, R., Rosenbaum, J., and Quispe, W. (2020). Excess mortality in the United States during the peak of the COVID-19 pandemic. MedRxiv. https://doi.org/10.1101/2020.05. 04.20090324

Rossen, L. M. (2020). Excess deaths associated with COVID-19, by age and race and ethnicity-United States, January 26-October 3, 2020. MMWR Morbidity and Mortality Weekly Report, 69, 1522-1527. https://doi.org/10.15585/mmwr.mm6942e2

Scully, E. P., Haverfield, J., Ursin, R. L., Tannenbaum, C., and Klein, S. L. (2020). Considering how biological sex impacts immune responses and COVID-19 outcomes. Nature Reviews Immunology, 20, 442-447. https://doi.org/10.1038/s41577-020-0348-8

Sebastiani, G., Massa, M., and Riboli, E. (2020). Covid-19 epidemic in Italy: Evolution, projections and impact of government measures. European Journal of Epidemiology, 35(4), 341-345. https://doi.org/10.1007/s10654-020-00631-6 
Sen, A. (1998). Mortality as an indicator of economic success and failure. The Economic Journal, 108(446), 1-25. https://doi.org/10.1111/1468-0297.00270

Signorelli, C., Scognamiglio, T., and Odone, A. (2020). COVID-19 in Italy: Impact of containment measures and prevalence estimates of infection in the general population. Acta Bio Medica Atenei Parmensis, 91(3-S), 175-179. https://doi.org/10.23750/abm. v91i3-S.9511

Stang, A., Standl, F., Kowall, B., Brune, B., Böttcher, J., Brinkmann, M., Dittmer, U., and Jöckel, K.-H. (2020). Excess mortality due to COVID-19 in Germany. The Journal of Infection, 81(5), 797-801. https://doi.org/10.1016/j.jinf.2020.09.012

The Lancet Oncology. (2020). Safeguarding cancer care in a post-COVID-19 world. The Lancet Oncology, 21(5), 603. https://doi.org/10.1016/S1470-2045(20)30243-6

Trias-Llimós, S., Riffe, T., and Bilal, U. (2020). Monitoring life expectancy levels during the COVID-19 pandemic: Example of the unequal impact of the first wave on Spanish regions. PLoS ONE, 15(11), Article e0241952. https://doi.org/10.1371/journal.pone.0241952

Vandoros, S. (2020). Excess mortality during the Covid-19 pandemic: Early evidence from England and Wales. Social Science $\mathcal{F}$ Medicine, 258, Article 113101. https://doi.org/10. 1016/j.socscimed.2020.113101

Weinberger, D. M., Chen, J., Cohen, T., Crawford, F. W., Mostashari, F., Olson, D., Pitzer, V. E., Reich, N. G., Russi, M., Simonsen, L., Watkins, A., and Viboud, C. (2020). Estimation of excess deaths associated with the COVID-19 pandemic in the United States, March to May 2020. JAMA Internal Medicine, 180(10), 1336-1344. https://doi.org/10.1001/ jamainternmed.2020.3391

Wilmoth, J. R., Andreev, K., Jdanov, D., Glei, A., and Riffe, T. (2019). Methods protocol for the human mortality database. The Human Mortality Database. https://www.mortality. org/Public/Docs/MethodsProtocol.pdf 


\section{Appendix}

\section{Figure A.1:}

Distribution of excess mortality in March-April 2020 across Italian provinces. The provinces in Lombardy are highlighted by the bold black line. The province of Piacenza is indicated by the blue arrow. Excess mortality is calculated as the percentage difference with respect to baseline mortality (2015-2019 average)

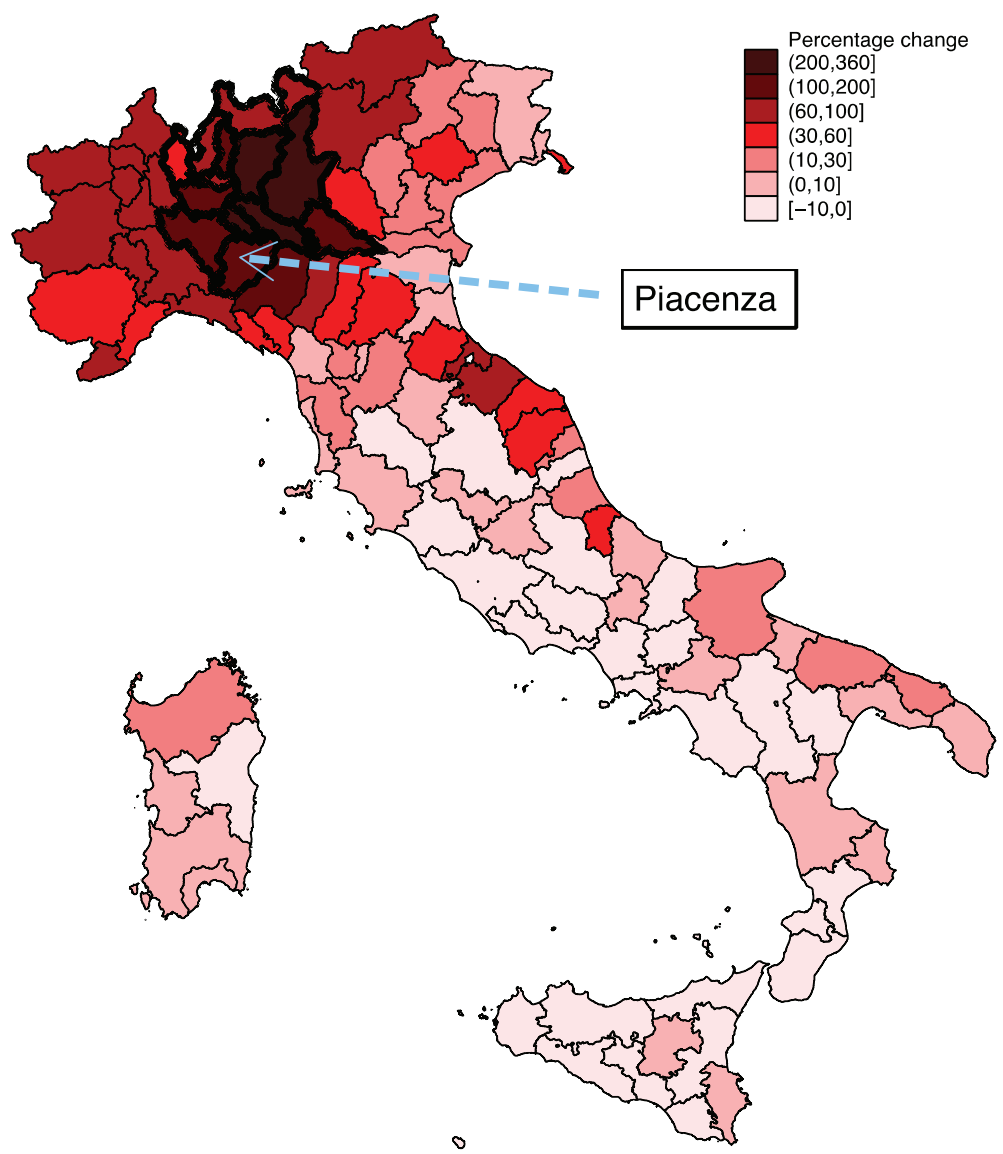


Figure A.2:

Distribution of excess mortality in March-April 2020 across municipalities in Lombardy and in the province of Piacenza

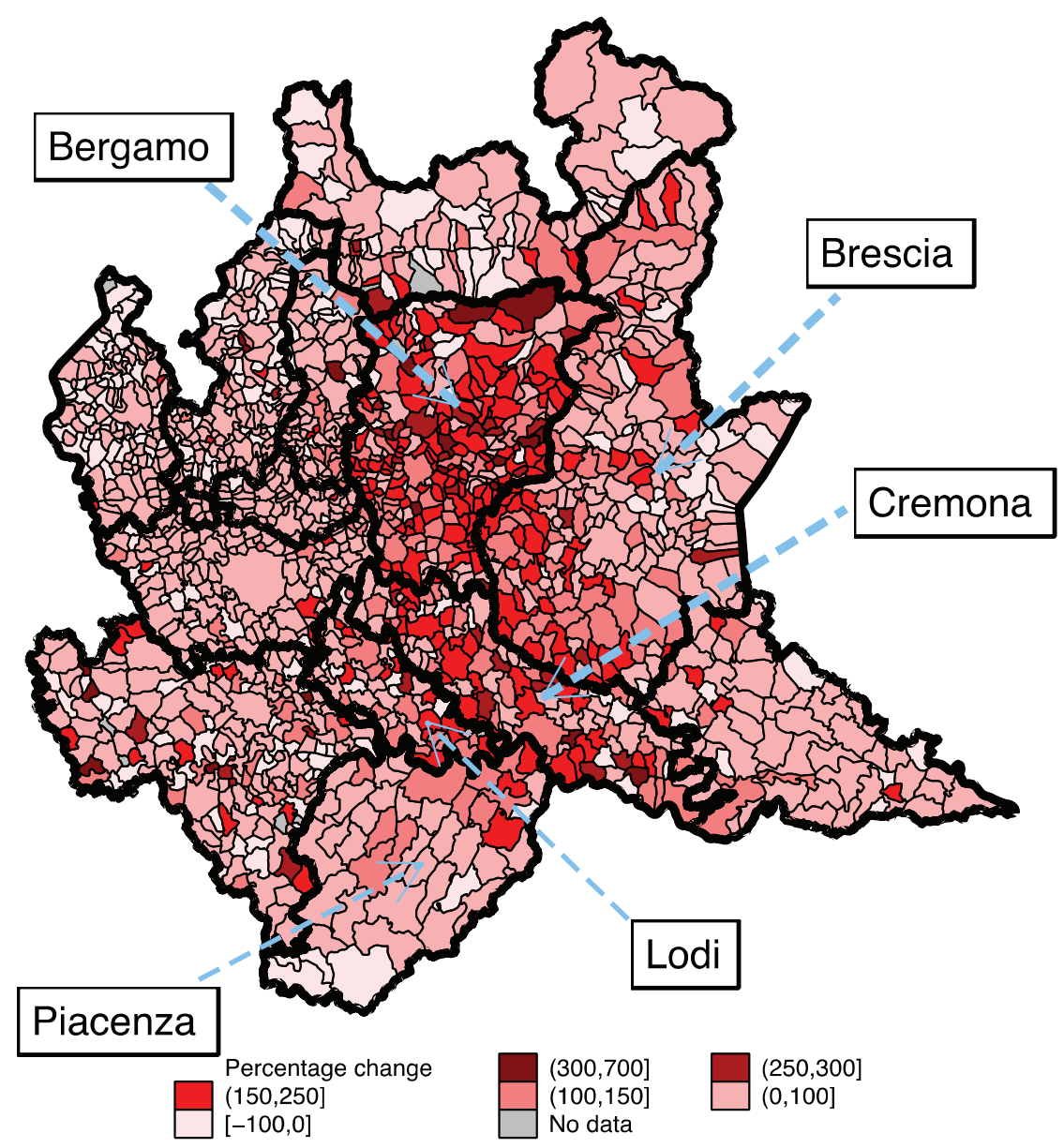


Figure A.3:

Decomposition of the loss of life expectancy in the first quadrimester, by age and sex and province

\section{Bergamo}

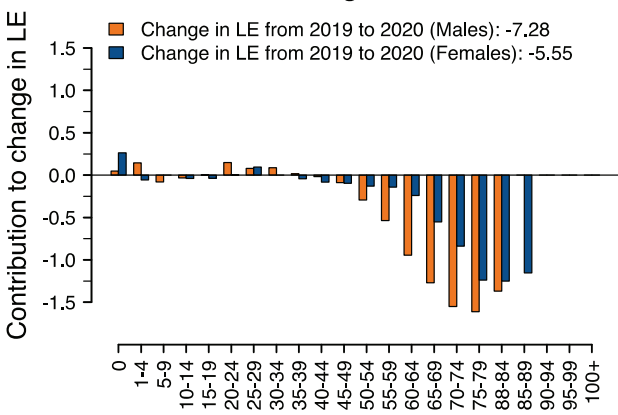

Cremona
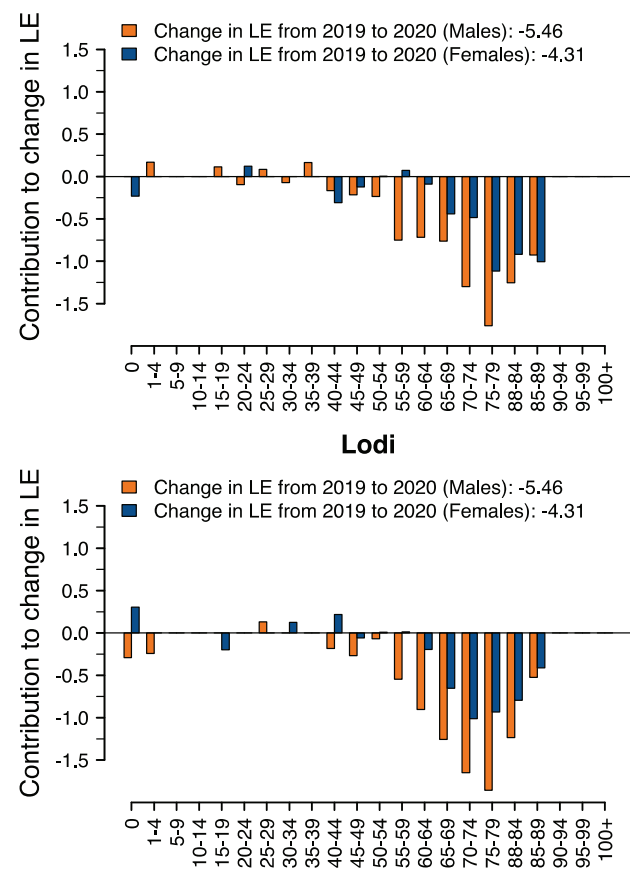

\section{Brescia}

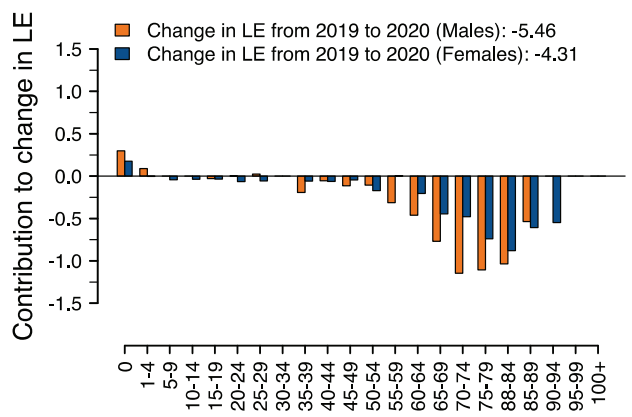

Piacenza

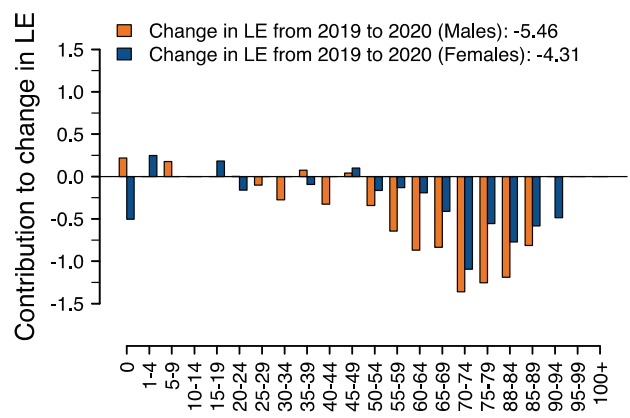

Lombardia

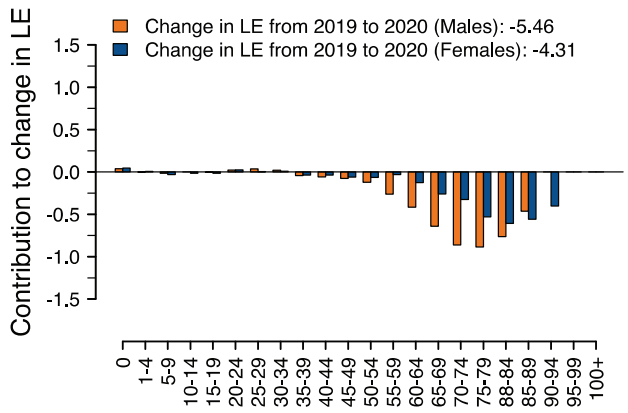

Note: For decomposing changes in life expectancy into age-specific contributions, the method proposed by Arriaga $(1984)^{3}$ is applied. This approach is used to assess which age-groups have primary contributed to the change in the first quadrimester life expectancy between 2019 and 2020

3 Arriaga, E.E. (1984). Measuring and Explaining the Change in Life Expectancies. Demography 21(1):83-96. doi: 10.2307/2061029. 
Table A.1:

Population exposure by province, year 2020

\begin{tabular}{|c|c|c|c|c|c|c|}
\hline $\begin{array}{l}\text { Age } \\
\text { class }\end{array}$ & $\begin{array}{c}\text { Pop } 2020 \\
\text { males } \\
\text { (beginning) }\end{array}$ & $\begin{array}{c}\text { Pop } 2020 \\
\text { males } \\
\text { (end) }\end{array}$ & $\begin{array}{c}\text { Exposure } \\
\text { males } \\
\text { (person-years) }\end{array}$ & $\begin{array}{c}\text { Pop } 2020 \\
\text { females } \\
\text { (beginning) }\end{array}$ & $\begin{array}{c}\text { Pop } 2020 \\
\text { females } \\
\text { (end) }\end{array}$ & $\begin{array}{c}\text { Exposure } \\
\text { females } \\
\text { (person-years) }\end{array}$ \\
\hline \multicolumn{7}{|c|}{ BERGAMO } \\
\hline 0 & 4140 & 4127 & 4133 & 4112 & 4100 & 4106 \\
\hline $1-4$ & 19110 & 19109 & 19110 & 17998 & 17995 & 17997 \\
\hline $5-9$ & 28054 & 28051 & 28052 & 26278 & 26277 & 26277 \\
\hline $10-14$ & 30073 & 30068 & 30070 & 28448 & 28445 & 28446 \\
\hline $15-19$ & 29875 & 29866 & 29871 & 27856 & 27854 & 27855 \\
\hline $20-24$ & 29701 & 29687 & 29694 & 27304 & 27300 & 27302 \\
\hline $25-29$ & 29134 & 29124 & 29129 & 27849 & 27845 & 27847 \\
\hline $30-34$ & 30332 & 30315 & 30323 & 30035 & 30029 & 30032 \\
\hline $35-39$ & 34293 & 34272 & 34283 & 33522 & 33512 & 33517 \\
\hline $40-44$ & 41078 & 41036 & 41057 & 39572 & 39537 & 39554 \\
\hline $45-49$ & 46720 & 46623 & 46671 & 43875 & 43822 & 43848 \\
\hline $50-54$ & 47710 & 47547 & 47628 & 45497 & 45399 & 45448 \\
\hline $55-59$ & 42755 & 42490 & 42622 & 42053 & 41917 & 41985 \\
\hline $60-64$ & 35011 & 34594 & 34802 & 35498 & 35304 & 35401 \\
\hline $65-69$ & 30921 & 30258 & 30589 & 32148 & 31859 & 32003 \\
\hline $70-74$ & 27929 & 26875 & 27402 & 30184 & 29695 & 29939 \\
\hline $75-79$ & 21009 & 19661 & 20335 & 25417 & 24570 & 24994 \\
\hline $80-84$ & 15480 & 13775 & 14627 & 21472 & 20105 & 20789 \\
\hline $85-89$ & 7733 & 6227 & 6980 & 14335 & 12483 & 13409 \\
\hline 90-94 & 2463 & 1696 & 2080 & 6901 & 5272 & 6087 \\
\hline 95-99 & 396 & 212 & 304 & 1918 & 1189 & 1554 \\
\hline $100+$ & 19 & 2 & 10 & 176 & 62 & 119 \\
\hline
\end{tabular}

Continued 
Table A.1:

Continued

\begin{tabular}{lcccccc}
\hline $\begin{array}{c}\text { Age } \\
\text { class }\end{array}$ & $\begin{array}{c}\text { Pop 2020 } \\
\text { males } \\
\text { (beginning) }\end{array}$ & $\begin{array}{c}\text { Pop 2020 } \\
\text { males } \\
\text { (end) }\end{array}$ & $\begin{array}{c}\text { Exposure } \\
\text { males } \\
\text { (person-years) }\end{array}$ & $\begin{array}{c}\text { Pop 2020 } \\
\text { females } \\
\text { (beginning) }\end{array}$ & $\begin{array}{c}\text { Pop 2020 } \\
\text { females } \\
\text { (end) }\end{array}$ & $\begin{array}{c}\text { Exposure } \\
\text { females } \\
\text { (person-years) }\end{array}$ \\
\hline \multicolumn{5}{c}{ (persen } \\
1-4 & 21513 & 21509 & 21511 & 20613 & 20610 & 20611 \\
$5-9$ & 30953 & 30952 & 30952 & 29459 & 29457 & 29458 \\
$10-14$ & 33484 & 33483 & 33483 & 31670 & 31669 & 31669 \\
$15-19$ & 32860 & 32853 & 32856 & 30250 & 30245 & 30248 \\
$20-24$ & 33324 & 33312 & 33318 & 30213 & 30206 & 30210 \\
$25-29$ & 33204 & 33192 & 33198 & 31884 & 31878 & 31881 \\
$30-34$ & 34943 & 34927 & 34935 & 34248 & 34243 & 34246 \\
$35-39$ & 39634 & 39598 & 39616 & 38994 & 38975 & 38984 \\
$40-44$ & 47140 & 47093 & 47116 & 45568 & 45537 & 45552 \\
$45-49$ & 53420 & 53340 & 53380 & 50503 & 50457 & 50480 \\
$50-54$ & 53368 & 53208 & 53288 & 51550 & 51451 & 51501 \\
$55-59$ & 47581 & 47314 & 47447 & 47426 & 47295 & 47360 \\
$60-64$ & 38707 & 38337 & 38522 & 39872 & 39701 & 39787 \\
$65-69$ & 33983 & 33421 & 33702 & 36128 & 35840 & 35984 \\
$70-74$ & 31695 & 30752 & 31223 & 34845 & 34372 & 34608 \\
$75-79$ & 24849 & 23609 & 24229 & 29843 & 29061 & 29452 \\
$80-84$ & 18232 & 16602 & 17417 & 25725 & 24384 & 25054 \\
$85-89$ & 8822 & 7382 & 8102 & 17175 & 15335 & 16255 \\
$90-94$ & 3022 & 2192 & 2607 & 9114 & 7157 & 8135 \\
$95-99$ & 516 & 292 & 404 & 2514 & 1621 & 2068 \\
$100+$ & 37 & 10 & 24 & 247 & 107 & 177 \\
\hline
\end{tabular}

Continued 
Table A.1:

Continued

\begin{tabular}{|c|c|c|c|c|c|c|}
\hline $\begin{array}{l}\text { Age } \\
\text { class }\end{array}$ & $\begin{array}{c}\text { Pop } 2020 \\
\text { males } \\
\text { (beginning) }\end{array}$ & $\begin{array}{c}\text { Pop } 2020 \\
\text { males } \\
\text { (end) }\end{array}$ & $\begin{array}{c}\text { Exposure } \\
\text { males } \\
\text { (person-years) }\end{array}$ & $\begin{array}{c}\text { Pop } 2020 \\
\text { females } \\
\text { (beginning) }\end{array}$ & $\begin{array}{c}\text { Pop } 2020 \\
\text { females } \\
\text { (end) }\end{array}$ & $\begin{array}{c}\text { Exposure } \\
\text { females } \\
\text { (person-years) }\end{array}$ \\
\hline \multicolumn{7}{|c|}{ CREMONA } \\
\hline 0 & 1299 & 1294 & 1297 & 1186 & 1181 & 1183 \\
\hline $1-4$ & 5567 & 5567 & 5567 & 5185 & 5185 & 5185 \\
\hline $5-9$ & 8152 & 8152 & 8152 & 7417 & 7417 & 7417 \\
\hline $10-14$ & 8674 & 8673 & 8673 & 7897 & 7896 & 7897 \\
\hline $15-19$ & 8414 & 8411 & 8412 & 7685 & 7684 & 7684 \\
\hline $20-24$ & 9036 & 9032 & 9034 & 8038 & 8035 & 8037 \\
\hline $25-29$ & 9189 & 9188 & 9189 & 8693 & 8692 & 8693 \\
\hline $30-34$ & 9684 & 9674 & 9679 & 9321 & 9320 & 9320 \\
\hline $35-39$ & 10738 & 10735 & 10737 & 10267 & 10261 & 10264 \\
\hline $40-44$ & 12943 & 12922 & 12932 & 12463 & 12451 & 12457 \\
\hline $45-49$ & 14326 & 14298 & 14312 & 13744 & 13730 & 13737 \\
\hline $50-54$ & 15146 & 15091 & 15118 & 14494 & 14461 & 14477 \\
\hline $55-59$ & 13560 & 13458 & 13509 & 13669 & 13623 & 13646 \\
\hline $60-64$ & 11665 & 11537 & 11601 & 12120 & 12058 & 12089 \\
\hline $65-69$ & 10668 & 10444 & 10556 & 10987 & 10883 & 10935 \\
\hline $70-74$ & 9967 & 9623 & 9795 & 10787 & 10625 & 10706 \\
\hline $75-79$ & 7496 & 7015 & 7256 & 9134 & 8821 & 8977 \\
\hline $80-84$ & 5986 & 5399 & 5692 & 8541 & 8018 & 8279 \\
\hline $85-89$ & 2955 & 2411 & 2683 & 5908 & 5141 & 5524 \\
\hline 90-94 & 1065 & 710 & 887 & 3095 & 2338 & 2716 \\
\hline 95-99 & 204 & 104 & 154 & 895 & 536 & 716 \\
\hline $100+$ & 9 & 3 & 6 & 78 & 33 & 55 \\
\hline
\end{tabular}

Continued 
Table A.1:

Continued

\begin{tabular}{|c|c|c|c|c|c|c|}
\hline $\begin{array}{l}\text { Age } \\
\text { class }\end{array}$ & $\begin{array}{c}\text { Pop } 2020 \\
\text { males } \\
\text { (beginning) }\end{array}$ & $\begin{array}{c}\text { Pop } 2020 \\
\text { males } \\
\text { (end) }\end{array}$ & $\begin{array}{c}\text { Exposure } \\
\text { males } \\
\text { (person-years) }\end{array}$ & $\begin{array}{c}\text { Pop } 2020 \\
\text { females } \\
\text { (beginning) }\end{array}$ & $\begin{array}{c}\text { Pop } 2020 \\
\text { females } \\
\text { (end) }\end{array}$ & $\begin{array}{c}\text { Exposure } \\
\text { females } \\
\text { (person-years) }\end{array}$ \\
\hline \multicolumn{7}{|c|}{ LODI } \\
\hline 0 & 855 & 851 & 853 & 836 & 835 & 836 \\
\hline $1-4$ & 3987 & 3984 & 3986 & 3827 & 3827 & 3827 \\
\hline 5-9 & 5576 & 5576 & 5576 & 5213 & 5213 & 5213 \\
\hline 10-14 & 5973 & 5973 & 5973 & 5470 & 5470 & 5470 \\
\hline $15-19$ & 5503 & 5503 & 5503 & 5331 & 5330 & 5330 \\
\hline $20-24$ & 5728 & 5723 & 5726 & 5275 & 5275 & 5275 \\
\hline $25-29$ & 5908 & 5906 & 5907 & 5742 & 5742 & 5742 \\
\hline $30-34$ & 6544 & 6542 & 6543 & 6338 & 6335 & 6336 \\
\hline $35-39$ & 7323 & 7320 & 7322 & 7085 & 7083 & 7084 \\
\hline $40-44$ & 8678 & 8671 & 8675 & 8410 & 8405 & 8407 \\
\hline $45-49$ & 9876 & 9856 & 9866 & 9284 & 9270 & 9277 \\
\hline $50-54$ & 10106 & 10069 & 10087 & 9737 & 9716 & 9727 \\
\hline $55-59$ & 8651 & 8604 & 8627 & 8477 & 8459 & 8468 \\
\hline $60-64$ & 7209 & 7128 & 7169 & 7444 & 7410 & 7427 \\
\hline $65-69$ & 6339 & 6213 & 6276 & 6629 & 6565 & 6597 \\
\hline $70-74$ & 5958 & 5737 & 5847 & 6429 & 6324 & 6377 \\
\hline $75-79$ & 4306 & 4031 & 4168 & 5373 & 5206 & 5289 \\
\hline $80-84$ & 3216 & 2875 & 3046 & 4828 & 4555 & 4691 \\
\hline $85-89$ & 1554 & 1284 & 1419 & 3062 & 2710 & 2886 \\
\hline 90-94 & 501 & 356 & 428 & 1491 & 1128 & 1309 \\
\hline 95-99 & 78 & 42 & 60 & 422 & 254 & 338 \\
\hline $100+$ & 8 & 5 & 6 & 27 & 9 & 18 \\
\hline
\end{tabular}

Continued 
Table A.1:

Continued

\begin{tabular}{|c|c|c|c|c|c|c|}
\hline $\begin{array}{l}\text { Age } \\
\text { class }\end{array}$ & $\begin{array}{c}\text { Pop } 2020 \\
\text { males } \\
\text { (beginning) }\end{array}$ & $\begin{array}{c}\text { Pop } 2020 \\
\text { males } \\
\text { (end) }\end{array}$ & $\begin{array}{c}\text { Exposure } \\
\text { males } \\
\text { (person-years) }\end{array}$ & $\begin{array}{c}\text { Pop } 2020 \\
\text { females } \\
\text { (beginning) }\end{array}$ & $\begin{array}{c}\text { Pop } 2020 \\
\text { females } \\
\text { (end) }\end{array}$ & $\begin{array}{c}\text { Exposure } \\
\text { females } \\
\text { (person-years) }\end{array}$ \\
\hline \multicolumn{7}{|c|}{ PIACENZA } \\
\hline 0 & 997 & 995 & 996 & 1058 & 1055 & 1056 \\
\hline $1-4$ & 4661 & 4660 & 4660 & 4241 & 4241 & 4241 \\
\hline $5-9$ & 6339 & 6338 & 6339 & 5984 & 5984 & 5984 \\
\hline $10-14$ & 6579 & 6579 & 6579 & 6273 & 6273 & 6273 \\
\hline $15-19$ & 6516 & 6515 & 6516 & 6060 & 6060 & 6060 \\
\hline $20-24$ & 7113 & 7110 & 7111 & 6202 & 6201 & 6201 \\
\hline $25-29$ & 7584 & 7580 & 7582 & 7059 & 7057 & 7058 \\
\hline $30-34$ & 7692 & 7685 & 7689 & 7516 & 7516 & 7516 \\
\hline $35-39$ & 8388 & 8385 & 8386 & 7950 & 7945 & 7947 \\
\hline $40-44$ & 9921 & 9908 & 9914 & 9596 & 9590 & 9593 \\
\hline $45-49$ & 11460 & 11445 & 11452 & 11493 & 11484 & 11489 \\
\hline $50-54$ & 11967 & 11919 & 11943 & 11736 & 11717 & 11727 \\
\hline $55-59$ & 10959 & 10893 & 10926 & 11054 & 11012 & 11033 \\
\hline $60-64$ & 9444 & 9331 & 9388 & 9725 & 9677 & 9701 \\
\hline $65-69$ & 7929 & 7797 & 7863 & 8374 & 8298 & 8336 \\
\hline $70-74$ & 7605 & 7358 & 7481 & 8583 & 8427 & 8505 \\
\hline $75-79$ & 6436 & 6069 & 6252 & 7707 & 7494 & 7600 \\
\hline $80-84$ & 5079 & 4597 & 4838 & 7076 & 6689 & 6882 \\
\hline $85-89$ & 2866 & 2397 & 2631 & 5158 & 4562 & 4860 \\
\hline 90-94 & 1043 & 753 & 898 & 2685 & 2055 & 2370 \\
\hline 95-99 & 202 & 126 & 164 & 831 & 526 & 678 \\
\hline $100+$ & 13 & 5 & 9 & 82 & 37 & 59 \\
\hline
\end{tabular}

Note: Population at the beginning of 2020 is provided by ISTAT. Population at the end of 2020 is estimated following the procedure outlined in the Methods section. Exposure (person-years) is given by the rounded average of population at the beginning and at the end of the year.

Open Access This article is published under the terms of the Creative Commons Attribution 4.0 International License (https://creativecommons.org/licenses/by/4.0/) that allows the sharing, use and adaptation in any medium, provided that the user gives appropriate credit, provides a link to the license, and indicates if changes were made. 